\title{
VI.
}

\section{Beitrag zur Kenntniss der Geschwülste der Submaxillar-Speicheldrïse.}

(Aus dem Pathologiseb-anatomiscben Institut in Wien.)

Von Dr. Georg Löwenbach.

(Hierzu Taf. II.)

Zwei kurz nach einander dem hiesigen pathologisch-anatomischen Institute übersandte Tumoren veranlassten mich in Folge der grossen Aehnlichkeit ibres klinischen, topographischen und pathologisch-histologischen Verhaltens zur genaueren Untersuchung derseiben.

Es handelt sich um Tumoren aus der Gegend der Submaxillardrüse, die bei der mikroskopischen Untersuchung sich als das erwiesen, was man seit geraumer Zeit als Cylindrom, Siphonom, Schlauchknorpelgeschwulst, plexiforme Myxosarcom, Schleimcancroid u. s. w. bezeichnet hat.

Die eigenthümliche Beschaffenheit der einzelnen Bestandtheile der Tumoren sowohl, als auch manche Einzelheiten ihres Aufbaues in toto, die sich bei genauerer Untersuchung ergaben, bestimmten mich, in der mir zugänglichen Literatur mich über verwandte Tumoren zu orientiren. Fasse ich die Ergebnisse dessen, was ich in der Literatur fand, zusammen, so kann dies unter verschiedenen Gesichtspunkten geschehen.

Znäächst einmal fragte ich mich über die Häufigkeit und Beschaffenheit derjenigen Tumoren, welche überhaupt in der Submaxillargegend vorkommen, also derjenigen Tumoren, welche ausgehen von der Glandula submaxillaris, sublingualis oder deren Nachbarschaft.

Hiebei stellt es sich heraus, dass, im Gegensatz zu den so häufigen Tumoren der Parotis bezw. der Parotisgegend, die uns interessirenden Geschwülste keineswegs zu den alltäglichen pathologischen Vorkommnissen gehören. 


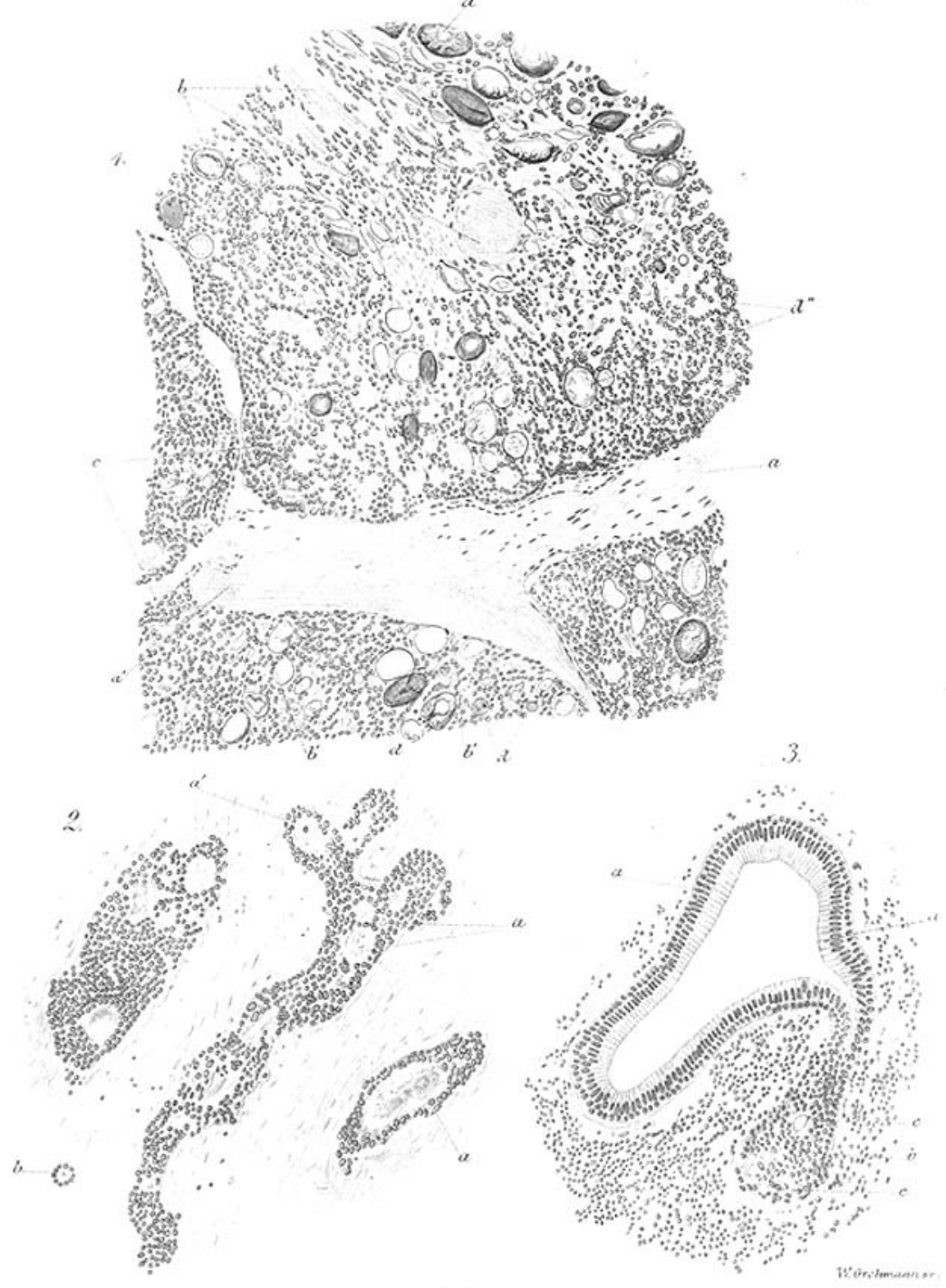


A I bert beschreibt in seinet Handbuca der Cairurgie $2 . B d$, alerdings rein klinisch, zwei Enchondrome der Submaxillaris.

v. Zeissl (Oesterr. med. Jabrbächer. 1881) beschreibt ein reines Adenom der Sublingualis.

D) uplay (Arch. gén. de Méd. 1875) und Ferreri (Bull. della Societá Lauzin di osp. di Roma. 1888) beschreiben Adenome der Submaxillardrüse.

Ruggi (Rivista clinica di Bologna. II. 4, 1872, cit. nach Schmidt's Jahrbüchern. 158): gleichzeitiges Vorkonmen von sogenannten "Cancroiden" in der Wange und in der Submaxillaris; welches der primäre Ausgangspunkt für deren Entstehung sei, lässt er in suspenso.

Verneuil (Gazette des hôpiteanx. 133. 1871) bespricht, allerdings nur klinisch, ein "Epitheliom" der Sublingualis.

Griffini-Trombetta (Atti della Reale accademia di scienze di Torino, 18. 1889) besprechen ein "Chondrocarcinoma" der Submaxillaris, nach der Beschreibung ähnlich den oft auch als Cbondro-Endotheliom bezeichnetea Hischgescbwülsten der Parotisgegend.

Barth (Ziogler"s Beiträge. Bd. 19) beschreibt ein Endotheliom der Unterungevgegend; Soblingualis atrophisch.

Volkmann (Deutsche Zeitschr. f. Chirurgie. Bd. 41) giebt eine Uebersicht der ihm bekannt gewordenen talle von Tumoren der Submaxillargegend wie folgt:
4 Carcinome
2 Sarcome
7 unklare Fälle
33 Myxo-Chondro-Endotheliome

(biéoei inbegriffen seine eigenen Fälle: 1 Carcinom, 1 Angiosarcom, 3 Endotheliome). Er citirt bei dieser Golegenheit:

Butlin, Transactions of the pathological society. 28

Butlin, Medical times and gazette. 1878

Oha intre, Gữu. des hồp. 1888

Nepveu, Bull. de la société de chir. 1879; diese beschreiben sämmtlich Myxochondrome.

Nasse spricht in seiner Abhandlung in Langen beck's Archiv Bd. 44 unter Fall 34-36 von 3 Chondro-Endotheliomen der Submaxilaris, nach Beschreibung und Bezeichnung von Mischgeschwïlsten der Parotisgegend analog. Ferner beschreibt er als Fall 40 ein Oylindrom, der Submaxillargegend; ein ebensolches als Fall 46, in welchem die Drüse selbst vollkommen frei war.

Billrotb (dieses Archiv. Bd. 17) beschreibt 17 Fälle von Tumoren der Speicheldrüsen, hauptsächlich der Parotis-, zum Theil anch der Submaxillargegend; er bezeichnet sie als Cylindrome und sie gehören $z u$ den ältesten derartigen Beobachtungen.

Ewald (Wiener klin. Wochenschr. 1897); Gylindrom des Zungengrundes. 
Klebs (Lebrbuch der Pathologischen Anatomie. II) spricht von einem Cylindrom der Submaxillargegend, bei Freisein der Drüse; nach der Operation Recidive.

v. Ewetzki (dieses Archiv. Bd. 69): analoger Fall, ebenfalls mit Recidiv nach der Operation.

Tommasi (dieses Archiv. Bd. 31) beschreibt einen sehr eigenartig gebauten, den Cylindromen zugezäblten Tumor der Submaxillargegend, der sich durch Metastasen als sehr malign erwies.

Franke (dieses Archiv. Bd. 121): Cylindrom der Submaxillargegend.

Rapok (Deutsche Zeitschr. für Chir. 30) erwähnt in einer klinischen Statistik neben 5 Parotis-Cylindromen auch ein Submaxillaris-Cylindrom.

Ausserdem beschreiben mebr oder minder ausführlich, meist vom klinischen Standpunkt aus, einfach als "Tumoren" der Submaxillargegend (cit. nach Volkmann):

Talaczek, Thèse de Paris. 1869

Gross, Revue méd. de l'Est. Nancy 1886

Gluge, Atlas der path. Histologie. 1877, S. 58

Herzfeld, Diss. Berlin 1893

Jouliard, Thèse de Paris. 1888

Rengueber, Courier médical. 1884.

Diese Zusammenstellung ergiebt also ungefähr 60-70 Tumoren der Sublingualis, Submaxillaris und ihrer Nachbarschaft, von den benignen bis $\mathrm{zu}$ den malignesten, recidivirenden, metastasirenden.

Unter diesen prävaliren vor allen, schon durch die 33 von Volkmann zusammengestellten, die als Myxochondrome, Myxochondroendotheliome, Chondroendotheliome bekannten Tumoren, deren Analogie mit den relativ häufigen Mischgeschwülsten der Parotisgegend, sowie mit den von Eisenmenger (Deutsche Zeitschrift f. Chirurgie. 39) beschriebenen 5 Mischtumoren des weichen und harten Gaumens unverkennbar ist. drome.

Nächst ihnen aber spielen hier die grösste Rolle die Cylin-

Ausser den von Billroth beschriebenen, in ihrer Anzahl nicht genau detaillirten, finde ich weitere 9 als Cylindrome der Submaxillaris beschriebene Tumoren. Während jene Mischgeschwülste sehr häufig, ja hauptsächlich nur in der Gegend der Speicheldrüsen vorkommen, bilden unter den Cylindromen im Allgemeinen die erwähnten Cylindrome der Submaxillargegend nur eine bestimmte Gruppe. 
Cylindrome kommen nehmlich in den verschiedensten Geweben und den verschiedensten Körperregionen vor. Yon vornherein ist es daher erklärlich, dass von so verschiedenen Standorten stammende, von so verschiedenen Geweben ausgehende Gebilde nicht unter allen Umständen den gleichen Charakter haben werden; und umgekehrt ist wieder zu schliessen, dass Tumoren von relativ grosser äusserer und mikroskopischer Analogie in ganz hervorragender Weise differiren, wenn man die Frago nach ihrer Pathogenese in's Auge fasst.

Man versteht im Allgemeinen und speciell nach der zuerst von Billroth gegebenen Definition unter Cylindromen Tumoren, welche aus 2 sich innig durchflechtenden Balkensystemen zusammengesetzt sind, von denen das eine aus Zellcylindern ("Keimcylindern"), das andere aus hyalin-schleimigen Cylindern oder Balken besteht.

Woher nun die zelligen Gebilde, woher die hyalinen, woher die schleimigen Theile der Tumoren stammen, darüber war man lange nicht einig, und auch heute noch differiren die Ansichten uber die "Cylindromfrage" erheblich.

Da nun gerade diese Frage bei der Untersuchung der zu besprechenden zwei Submaxillaristumoren von hauptsächlichem Interesse ist, so war ich bestrebt, aus der Literatur möglichst viele Fälle von Cylindromen, welcher Körperregion immer, herauszusuchen and mich iber die Ansicht der betreffenden Autoren bezigglich Morphologie und Pathogenese ihrer Fälle, sowie des Cylindroms im Allgemeinen zu orientiren. Hiebei kommen folgende Autoren in Betracht:

v. Fippel (Ziegler's Beiträge. Bd. 14): Angiosareom der Fossa poplitean

$\checkmark$. Kahlden (ebenda): Myosarcom, in Cylindrom äbergebend.

Steudener (dieses Archiv. Bd. 42):

1) Cylindrom der Brustdrüse

2) Cylindrom der Nasenwurzel.

Pagenstecher (dieses Archiv. Bd. 47): Cylindrom der Nasenwurzel.

Kocher (dieses Archiv. Bd.44): Scblauchsarcom im Stirnbein.

Böttcher (dieses Archiv. Bd. 38): Cylinorowe der linken Orbita.

Grohé, Bardeleben's Lehrbuch der Chirurgie. Bd. 1, S. 508.

Koester (dieses Archiv. Bd. 40): Epulis.

Becker (Bericht über die Augenklinik der Wiener Universität 1867): "Adenoid" der Thränendrüse. 
Maier (dieses Archiv. Bd. 14): sarcomatöser Duraltumar, von ihm als "walignes Papillom" bezeichnet.

Koschier (Wiener klin. Wochenschr. 1896): Tumor der Trachea: Carcinoma cylindromatosum.

Dembowski (Deutscbe Zeitscbr. für Chir. 32): cylindromähaliches Epitheliom der Augen-, Stirn- und Nasenhöhle.

Sasse (Archiv für klin. Chir. 54): Adenom der Mamma.

v. Oblen (Ziegler's Beiträge. Bd. 13): Parotiscylindrom.

Santesson (cit. nach Centralbl. für Chir. 19, schwedisch): Sarcoma plexiforme byalineum des Zungengrundes.

Narehand (Ziegler's Beiträge. Bd. 13); Oglindroma antri Highmori.

Rusticzky (dieses Archiv. Bd, 59): Duraltumor.

Lü cke (dieses Archiv. Bd. 35): 1) Tumor ossis metacarpi V, 2) Zungentumor, 3) centrales Osteosarcom des Humerus.

Nasse (Langenbeck's Archiv Bd. 44) Fälle 43, 44: Cylindrome der behaarten Kopfbaut.

Volkmann (dieses Archiv. Bd. 17): Tumor der Nasen- und Infraorbitalgegend.

Tizzoni (Arch. per le scienze med. VII) beschreibt ein „Epitelioma a globi ialini": Cylindrom der Haut, von der Epidermis ausgebend; die hyalinen Gebilde entstehen zum weitaus grössten Theil aus degenerirenden Epithelzellen.

Volkmann (Deutsche Zeitschr. für Chir. 41): Fall 11 Parotiscylindrom.

Poncet (Rerue de chir. 1890): wultiple Cylindrome der Kopfhaut.

Micheli (Lo Sperimentale. IV): Mammacylindrom bei einem Mann.

Kaufmann (Langenbeck's Archiv. Bd. 26): Parotiscylindrom.

Mumssen (Diss. Göttingen 1874): Adenomyxosarcoma parotidis.

König (Lehrbucb der Chir. Berlin 1875, Bd. 1): Sarco-chondroadenoma parotidis.

Ehrendorfer (Langenbeck's Archiv. Bd. 26): cylindromähnlicher gestielter Tumor des Pharynx.

Chiari (Oesterr. med. Jahrbücher. 1881): cylindromäbnlicher Tumor der Parotis.

Heschl (Wiener med. Wochenschr. 1877): Cylindrom der Lunge.

Maier (Archiv der Heilkunde. III): Dnralcylindrom.

v. Ewetzky (dieses Archiv. Bd. 69): Tumor der Orbita.

Friedreich (dieses Arcbiv. Bd. 27): Tumor der Wange.

Bennecke (Deutsche Zeitschr. für Chir. 42): centraler Kiefertumor.

Malassez (Arehives de physiologie normale et patbologique. III. 5, 6): desgleicben.

Lubarsch (dieses Archiv. Bd, 122).

Ganguillet (Diss. Bern 1878): Cylindrom des Conus medullaris.

Sattler, Ueber dus Cylindrom u. s. w. Berlin 1874.

Lubarsch (dieses Archiv. Bd. 111): cylindromähnliches primäres Carcinom der Lieberkühn'schen Drüsen im Ileum. 
Barlow (Deutsche Zeitschr. für klin. Medicin. 55, Festschrift für Zenker): Adenoma sebaceum.

Man kann nun die Ansichten, welche diese Autoren in Betreff der Pathogenese ihrer Tumoren einnehmen, in mehrere Gruppen bringen. Hiebei kommt von vornherein die Verschiedenheit der zwei Hauptbestandtheile in diesen Tumoren in Betracht, der zelligen Gebilde anf der einen, hyalin-schleimigen und der bindegewebigen auf der anderen Seite.

Von der einen Seite wird nun behauptet, die Zellen seien epithelialer Natur, die hyalinen Massen werden dann theils als Produkte irgendwelcher Veränderungen an den Zellen angesehen, theils als vom präformirten Bindegewebe herstammend.

Auf der anderen Seite steht die Ansicht, die Zellen hätten mit epithelialen Gebilden nichts zu than; über ihre genanere Genese gehon aber die Ansichten hier wieder auseinander. Knorpel-, Muskelzellen, Bindegewebskörperchen, Saftkanälchenzellen, Lymphgefäss- und Blutgefässendothelien oder Endothelien ohne nähere Classification, Perithelien - alle diese so verschiedenartigen Factoren werden von dieser Seite als Ausgangspunkte der Cylindrome angenommen, und diese consequenter Weise als sarcomatöse, eventuell als endo- oder peritheliale Tumoren angesehen. Die hyalinen Gebilde werden auch hier zum Theil als Produkte der Tumorzellen, zum Theil als directe A brömmlinge des bindegewebigen Stromas angesehen; eine dritte Ansicht aber lässt sie aus Gefässen hervorgehen, die in toto sich derartig veründern.

Ein kurzer Veberblick soll die Stellung der einzelnen Autoren zu dieser Frage kennzeichnen, wobei ich zunächst diejenigen anführe, welche sich für eine epitheliale Genese aussprechen.

Steuderer beschreibt ein Cylindrom der Mamma, welches er als aus einem Adenom hervorgegangen ansieht:

Sasse: Tumor manmae, beschrieben als Adenom mit cystisch-schleimiger Degeneration der Zellen und sehleimig-byaliner Degeneration der Gefässe, welcher exentuell als Epitbelioma cylindromatosum za bezeichnen würe.

Becker beschreiot einen eylindromähnlichen Tumor der Orbita, von ihm als "Adenoid der Thränendrüse ${ }^{\text {th }}$ bezeichnet.

y. Dembowski, Tumor der Augen-, Stirn - und Nasenböble, erk]ät als von dem Flimmeropithel ausgehendes Epitheliom mit a) schleimiger Zelldegeneration, b) schleimig-byaliner Bindegewebsdegeneration.

Volkmann, Cylindrom der Nasen- und Infraorbitalgegend, wahrschein- 
lich epithelialer Natur, dessen hyaline Massen als Zellprodukt anzuseben seien.

Koschier beschreibt einen biebergebörigen Tumor der Trachea, ansgebend von deren Cylinderepithel nach vorausgegangener Metaplasie desselben in Plattenepithel; die hyalinen Massen sind bindegewebiger Ablunft. Bezeichnet als Carcinoma cylindromatosum.

Lücke's Fall 1: cylindromatöser Tumor am 5. Mittelbandknochen, epithelialer Natur. Er lässt in suspenso, ob der Tumor nicht ein von den Schweissdrüsen ausgebendes Carcinom sei.

Barlow beschreibt in seiner Arbeit über „Adenoma sebaceum" der Haut byaline Gefäss- und Bindegewebs-Degenerationen, welche, wie er selbst sagt, an äbnliche Vorkommnisse in Cylindromen erinnern.

Nasse's Fälle 43, 44: Cylindrome der behaarten Kopfhaut, wahrscheinlich epithelialer Natur, Zusammenhang mit der Epidermis aber nicht nachgewiesen. Seine Fälle 3 und 4, beschrieben als Parotisadenome, sowie die duzu gehörige Fig. 2, erinnern in Beschreibung und Abbildung an Cylindrom.

Chiari beschreibt ein sogenanntes Gystosarcoma pbyllodes der Parotis, von ibm histologisch als Adenomyxom bezeichnet; ,hervorzuheben ist... die exquisite Aehnlichkeit... mit den sogenannten Cylindromen".

Bennecke sagt, dass in centralen Kiefertumoren (Epithelioma Adamantinum) zuweilen durch Zellmetamorpbosen eylindromähnliche Bilder zustandek ommen.

Malassez äussert sich ebenso.

Lubarsch beschreibt ein primäres Carcinom der Lieberkühn'schen Drüsen im Ileum, hineinwuchernd in die Lymphwege, deren Wände byalin degeneriren. Auch einzelne Tumorzellen zeigen "colloide" Beschaffenheit, das Ganze wird so cylindromähnlich, dass er im Hinblicke auf mehrere andere analoge Fälle in seiner Epikrise erk]ärt: "es giebt cylindromartige Tumoren, welche ächte Carcinome sind".

Hiemit wäre die eine Reihe von Arbeiten erschöpft, in denen das Epithel, gleichgültig welches Organs, als Ausgangspunkt von cylindromatösen Bildungen angesehen wird. Ich will nur ganz kurz bemerken, dass Tumoren der Submaxillarisgegend in dieser Gruppe bis nun absolut fehlen.

Beginnen wir die dieser gegenüberstehende Reihe von Autoren mit

Steudener. Er beschreibt ein Cylindrom der Nasenwurzel, nach seiner Ansicht von Gefässendothelien ausgehend. Die Zellcylinder zeigen oft hyaline Verquellung einzelner Zellen und sogar ächte Lumina, daher auch drüsenähnliche Anordnung.

Pagenstecher, cylindromähnlicher Tumor der Nasenwurzel, Ausgangspunkt: die Lymphgefässendothelien.

Marchand kommt gelegentlich der Besprechung eines Cylindroma 
antri Highmori zu dem Resultat, dass die Zellen ron den Bindegewebszollen abstammen; das Byalin stamme einerseits ebenfalls von Bindegewebe, andererseits sei es Zellprodukt.

Maier beschreibt als "malignes Papillom" einen von ihm ausdrucklich "sarcomatos" genannten Duraltumor mit hyaliner Gefässdegeneration, welche ein cylindromartiges Aussehen bedingt.

Maier beschreibt ein Duralcylindrom mit bindegewebiger Genese der Gylinder.

v. Oblen beschreibt ein Parotiscylindrom, welches er von den Bindegewehszellen ausgehen lässt; das Hyalin stammt einerseits von Bindegewebe, andererseits sei es Zellprodukt.

Volkmann's Fall 11: Oylindrom der Parotis, nach seiner Ansicht endotbelialer Herkunft, bemerkenswerth durch eigenthümlicbe, theils hyaline, theils concentrisch gestreifte Antbeile, welche als ringförmige Hüllen einzelne Zellhaufen umgeben. Dies erinnert an die Beschreibung ron

Friedreich, welcher ein böchst merkwürdiges und mit Ausnahwe einer später zu besprechenden Beobachtung yon Tommasi einzig dastehendes "Scblauchsarcom der Wange" bescbreibi. Dasselbe bestebt nehmlich aus durch einander gewundenen hyaiinen Schläuchen und Kapseln, welche ein von Zellen erfülltes Lumen einschliessen. Ausgangspunkt sei das Bindegewebe der Wange; die hyalinen Massen seien Produkte der Zellen.

Ka ufmann"s Fall 26: Parotiseplindrom. Ausgangspunkt seien die Saftkanälchen, das Iyalin stamme wenigstens zum Theil von der Unwandlung von Gefässen her. Im Allgemeineu sagt er: „Die sogenannten drüsenähnlichen Bildungen sind als Sarcombildungen aufzufassen, und die Fälle von Chondro-Adenom als Chondro-Sarcom."

Hisen menger beschreibt als dem Cylindrow setr nahestehend 5 Tumoren des weichen und harten Gaumeas, Tumoren wie sie an dieser Stelle bis dahin yon den Franzosen als Adénomes beschrieben wurden. Er giebt

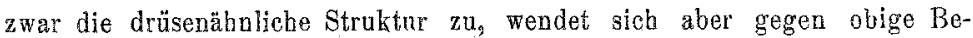
zeichnung and fübrt die Eatstehung dieser Geschwülste auf die Endo- und Perithelien zurück; seine Bezeichnung lautet „plexiforme Sarcome mit byaliner Gefässdegeneration". Da sich jedoch in diesen Tumoren mitunter rein myxamatöse und knorpelige Antheile fucien, so erinuern sie ungemein an ähnliche Tumoren der Paratisgegend und würden also als Mischgescbwülste mit ungewobnlicher Localisation zu einer Gruppe ganz anderer als der bier zu besprechenden Tumoren in Beziehung zu bringen sein.

Ehrendorfer beschreibt unter Hinweis auf das cylindromänliche Aussehen ein "plexiformes Sarcom des Pharynx" (gestielter Tumor) mit centraler hyaliner Degeneration der einzelnen Stränge und daher oft drüsenähnlichen Bildern. Eine Metastase dieses Tuwors zeigt keine solchen Bilder, Lein Eyalin, dagegen Lymphgefässendothelwucherungen in krebsperlenähnJicher Form.

Heschl beschreibt einen eigenthümlichen Tumor der Lunge: Cylindrom, bestebend nur aus byalinen Cylindern, deren Ausgangspunkt wahrseheinlich 
die elastischen Fasern, teinesfalls aber irgendwelche zelligen Gebilde seien. Er bezeichnet es als Cylindro-Desmoid, im Gegensatz zu den Billroth'schen Tumoren, die er als Cylindro-Myxome und Cylindro-Angiome definirt.

Kocher, "Schlanchsarcom" des Stirnknochens mit hyalinen Massen, die ibre Entstebung einer totalen Degeneration von Blutgefässen verdanken.

Lücke beschreibt als "Geschwulst in hyaliner Degeneration oder Cylindrom" einen Tumor des Humerus, der rein histologiseb von ibm als "centrales Osteosarcom" bezeichnet wird.

จ. Hippel, Tumor der Fossa poplitea, von den Endothelien der Saftkanälchen und Lymphgefässe ausgebend, mit cylindromähnlicher Struktur, besonder's in. den Lymphgefässen ganz drüsenäbnliche Bilder zeigend; er bezeichnet ihn als Angiosarcom.

Grohé bespricht die Entstehung der byalinen Massen in Cylindrom und lässt sie vom Stroma berstammen.

Sattler behauptet in seiner grundlegenden Arbeit über diese Tumoren deren bindegewebige Genese und sarcomatöse Natur. Er ist sich aber ihrer morphologischen und genetischen Sonderstellung bewusst und schlägt in vermittelnder Absicht den Namen, Sarcoma carcinomatodes" vor, welche Bezeicbnung jedoch in dieser Form, weil Verwirrung zu schaffen geeignet, sich nicht einzubürgern vermochte.

Wir kommen nun zu einer Reihe von unter sich und den übrigen sehr abweichenden Ansichten über die Genese der Cylindrome.

v. KahIden beschreibt ein Myom, welches stellenweise zu Myosarcom wird. In diesem finden sich nun cylindromatöse Antheile, deren Fyalin, da es sich nach der van Gieson'schen Methode roth färbt, von v. Kahlden als aus Bindegewebe bervorgehend angeseben wird.

$\mathrm{L} u ̈ \mathrm{cke}$ beschreibt sogar ein Cylindrom der Zunge, wo er an ein directes Entstehen der hyalinen Massen aus der Musculatur denkt.

Böttch er bescbreibt einen cylindromartigen Tumor. der linken Orbita mit zelligen und byalinen Cylindern; erstere sollen von Gefässendothelien, letztere dagegen vom Knorpel stammen.

Billroth beschreibt 12 Cylindrome der Parotis und Submaxillarisgegend mit zum Theil drüsenäbnlichen Bildern. Trotz eifrigen Suchens konnte er keine Uebergänge zwischen Drüse und Tumor im mikroskopischen Bilde finden, jedoch auch nicht vom Bindegewebe zum Tumor. Er lässt das Hyalin sowohl durch Secretion von Tumorzellen als auch durch Degeneration des Bindegewebes entstehen, von welch' beiden Vorgängen der Endeffekt histologisch der gleiche sei: Entstebung gleichmässig hyaliner Massen.

Während Billrotb die Frage nach der Pathogenese der Oylindrome unentschieden und nach zwei Seiten hin offen lässt, beantwortet Lubarsch dieselbe nach diesen beiden Seiten hin positiv: Sarcome und Carcinome könen zu Cylindromen werden; das Cylindrom ist keine einbeitliche Geschwulst. 
Rusticky bespricht eine seiner Beschreibung nach von allen äbrigen abweichende cylindromatöse Geschwulst der Dura. Als Ausgangspunizt bezeichnet er die Gefăssendothelien und nimmt zunächst eine Metaplasie dieses Endothels in Epithel und sodan Tumorbildung aus diesem metaplastischen Epithel an. Die hyalinen Antheile hält er für zellige Produkte.

Während wir im Vorhergehenden über Tumoren verschiedenster Körpertheile kurz referirten, wollen wir nun die Ansichten speciell über die Cylindrome der Submaxillargegend durchgehen. Ausser den Speicheldrüsentumoren von Billroth gehört hieher zunächst der von

Köster als cylindromatöse Epulis beschriebene Tumor, welcher die ihra benachbarte Sublingualis verschonte und als von den Lymphgefässendothelien ausgebend angesehen wurde. Die hyalin-schleimigen Antheile erklärt er als durch Degeneration einzelner Zellen entstanden. Die Bill roth'sche Errklärung der Rntstehung der byalinen Massen aus ganzen Gefässchen modificirt er dabin, dass er sie als hyalin degenerirende perivasculäre Lymphgefüsso auffisst.

Volk mann führt in seiner Tabelly der Submaxillartumoren unter seinen 5 eigenen Fällen 3 Endotheliome und 1 Angiosarcom an, welchen den Cylindromen nahestehen. Bei Besprechung letzterer führt er als Ausgangspunkt für die hyalinen Massen 3 Möglichkeiten der Entstehung an; aus rein zelligen, aus bindegewebigen Theilen und aus Gefässen.

Barth bespricht ein mit Atropbie der Sublingualis einhergehendes Endotheliom des Mundböhlenbodens.

Lit ald beschreibt ein recidivirendes Cylindrom des Zungengrundes, welchem er ondotheliale Herkunft vindicirt.

Santess on beschreibt einen cylindromartigen Tumor des Zungengrundes, bezeicbnet als Sarcoma plexiforme byalinum.

v. E we $₫ \mathrm{z}$ y, recidivirender Tumor der Submaxillargegend (ferner noch ein zweites Cylindrom der Orbita). Er hält beide Cylindrome für von den Saftkanälchenzellen ausgehend, das Hyalin im Allgemeinen für vom Bindegewebe abstammend, doch findet er im Recidiv des Submaxillartumors Alveolen mit "colloidem" Inbalt, dessen Entstebung er auf Zelldegeneration zurückführt. Der Orbitaltumor bat ausserdem "stellenweise zellige Stränge, yon hyalinen, undeutlich streifigen Scheiden umgeben (Taf. III. Fig. 16) " ... „diese Stellen zeigen ... Aebnlichkeit mit dem Fall von Friedreich“.

Tommasi beschreibt einen ebenfalls dem Friedreich'schen Wangentumor äbnlichen ron der Submaxiliargegend, mit Metastasen. Ausgangspunkt: die Saftkanälehen. Eir beschreibt eingehend die "physaliphore" Unwandlung und Aufstellung einzelner Zellen, ihr eventuelles Hoblwerden mit Entstebung von Zellen innerhalb der alten Kapseln, eventuelle Entstehung von Tochterkapseln mit neuen Zellen und "physaliphorer" Umwandlung auch dieser letzteren - wohl der complieirtest gebaute inter allen bekannt gewordenen cylindromatösen Tumoren.

Franke, Cylindrom der Submaxillargegend, bestehend aus zelligen 
Schläuchen, welche von byalinen Massen 1) durchzogen, 2) umscheidet werden und in welchen 3) einzelne Zellen hyalin degeneriren. Ausgangspunkt: die Endothelien, und zwar wabrscheinlich die Lymphgefässendothelien, weshalb er für seinen Tumor die Bezeichnung Angiosarcom abweist.

Klebs besebreibt ein Cylindrow der Submaxillardrüse, welches die Drüse selbst frei liess, und als dessen Ausgangspunkt er die Endothelien in der Kapsel der Submaxillardrüse ansiebt; bezeichnet als Endothelioma byalinum.

Nasse's Fall 46: malignes Cylindrom der Unterkiefergegend bei frei bleibender Drüse. Er kann den Ursprung des Tumors weder auf die epithelialen Gebilde der benachbarten Haut, noch auf das Bindegewebe, noch auf die Endothelien der Nachbarschaft zurückführen.

Wir sehen aus diesem Auszuge aus der Literatur, dass betreffs der Cylindrome im Allgemeinen die Ansichten über die Herkunft dieser Tumoren stark differiren und dass das punctum saliens der ganzen Controverse darin gelegen ist, ob diese $\mathrm{Tu}$ moren als epithelialer oder nicht epithelialer Herkunft anzusehen seien, ein Gegensatz, über welchen sich nur wenige hinwegsetzten, am präcisesten Lubarsch, indem er die Möglichkeit einer cylindromatösen Umwandlung von Sarcomen wie von Carcinomen zugiebt. Während also auf die Frage, ob epithelialer oder nicht epithelialer Natur, betreffs der Cylindrome im Allgemeinen keine einheitliche Antwort gegeben werden kann, bemerken wir bei Durchsicht der speciell auf die cylindromatösen Tumoren der Submaxillargegend bezüglichen Arbeiten, dass (abgesehen von dem von Nasse in dieser Richtung unentschieden gelassenen Falle) die Möglichkeit einer epithelialen Genese derselben eigentlich von Niemand behauptet wurde; sondern wir sehen als ausschliesslich anerkannte Generation dieser Geschwülste: die Bindegewebszellen, die Lymphgefässendothelien und die sogenannten Saftkanälchenzellen der Kapsel und weiteren Umgebung der Submaxillardrüse.

Wen dieser Befund, erhoben an allerdings nahezu einem Dutzend einander sehr nahe stehenden Tumoren derselben Körperregion dazu verleiten könnte, seine Ansicht über dieselben, bezw. über ihre Pathogenese zu schematisiren und die Möglichkeit ihres epithelialen Ursprunges zu negiren, den möge nachfolgende Untersuchung davon überzeugen, dass es, wie bezüglich der Cylindrome überhaupt, so auch betreffs der in dieser Region vorkommenden eben kein Schema giebt, und dass bei Besprechung 
dieser Tumoren die Möglichkeit einer Entstehuvg aus epithelialen Gebilden auch in dieser Körperregion nicht ohne weiteres von der Hand zu weisen ist.

Loh gebe nun eine eingehende Beschreibung von awei 'Tumoren der Submaxillarisgegend in grob-pathologisch-anatomischer und in mikroskopischer Hinsicht, und füge die Krankengeschichten, sowie ich dieselben von den Kliniken erhielt, bei. Für die freundliche Ueberlassung derselben erlaube ich mir an dieser Stelle Herrn Hofrath Prof. Gussenbauer und seinem Assistenten Herrn Dr. Pupovac einerseits, Herrn Docenten Dr. Fränkel, Abtheilungsvorstand der Allgemeinen Poliklinik, andererseits, meinen ergebensten Dank auszusprechen.

I. Anna T., 36 Jabre alt, verheirathet, Postdienersfran ans Datschitz in Mäbren, wurde am 25. Januar 1897 auf die IX. Abtheilung für chirurgische Krankheiten (Docent Dr. Frã nkel) der Wiener Allgeneinen Polikhinils wegen eines zu operirenden Tumors am Halse anfgenommen (Prot. No. 30, 1897).

Dis Anamnese besagt: Patientin besitzt seit ibrer Kindheit eine unter und am linken Unterkieferwinkel sitzende Gesehwulst von der Grösse einer Bohne; nach der Angabe der Patientin soll dieseibe in den letzten 3 Jahren langsam zu ihrer nunmehrigen Grösse herangewachsen sein.

Der am 25. Januar 1897 aufgenommene Status praesens ergiebt an der mässig kräftigen Frau eine Geschwulst von gut Hübnereigrösse, welche in die Tiefe bis zum Kehlkopf reicht, nach unten in die Fossa carotica übergeht. Dieselbe ist bei äusserlichem Zufühlen von grobböcteriger, barter Beschaffenheit, schmerzt auf Drucls ungemein starts. Die Baut äber dieser Geschwulst ist leicht versebiebbar und von normalem Aussehen und normaler Beschatfenheit.

Klinisehe Diagnose: Tumor regionis submaxiliaris.

Therapie: In ruhiger Narkose (mit Billroth'seber Mischung) wurde am 26. Januar 1897 die Exstirpation des Tumors ausgefübrt (Docent Dr. Fränkel). Die Blutung war mässig. Naht und Jodoformverband.

Am 31. Januar wurden die Nähte entfernt. Beilung per primam.

Ausgang der Behandlung: Patientin gebeilt entlassen am 2. Februar 1897.

\section{Pathologisch-anatomischer Befund.}

Das dem hiesigen patbologiseh-anatomisehen Institut zur Untersuchung übersandte Präparat erweist sich als eine Aftermasse von ungefähr Apfelgrösse, bestehend aus einem eirunden Theil von gut Hübnereigrösse, welcher das Centrum der Geschwulst und augleich die Hauptrasse derselben ausmacht, und aus zwei an gegenüberliegenden Seiten von diesem Haupttheil 
abgehenden, fingerförmigen Fortsätzen, der eine von ungefähr 2, der andere von $3 \mathrm{~cm}$ Länge; die Dicke des letzteren beträgt an den dem Centraltumor benachbarten Partien $3 \mathrm{~cm}$, an seinem Ende $1 \mathrm{~cm}$.

Die Oberfläche des Tumors ist an allen Partien desselben von leicht böckeriger Beschaffenheit. Die Farbe an der Oberfläche ist an manchen Stellen grau, an anderen eine grauweisse. Der Glanz ist dem einer Speckleber oder Speckmilz vergleichbar. Die Consistenz ist weehselnd, bald sehr hart, fast knorpelhart (an den dunkleren Partien), bald weicher (an den hellen Stellen), aber nirgends von etwa besonders hervorzuhebender Weichbeit.

Auf Durchschnitten gestaltet sich das makroskopische Bild etwas variabler. Abgeseben von einigen Partien, wo das Gewebe, augenscheinlich durch kleine Blutungen, einen rothgelbgrauen Farbenton zeigt und anfgelockert ist, zeigt sich die Hauptmasse des Tumors grob anatomisch aus 2 Componenten aufgebaut. Die eine wird von straffem Bindegewebe gebildet, welches in seinen 1 bis 3 , auch 5 bis $10 \mathrm{~mm}$ im Durchmesser haltenden Maschen und Lücken als zweiten und charakteristischen Bestandtheil der Geschwulst eine harte Masse von grauer Farbe enthält. Dieselbe ist sebwer schneidbar und von einem eher glasig als speckig zu nennenden Glanze.

An einigen Stellen ist von diesem grobalveolären Bau nichts zu sehen. Dort besteht der Tumor nur einzig und allein aus dieser soeben beschriebenen, eigenthümlich homogenen Substanz, ohne feinero Felderung durch gewöhnliches Bindegewebe. Solche Stellen sind etwas dunkler grau und noch härter als die anderen, und entsprechen auch den bei Beschreibung der Oberfläche erwäbnten härteren grauen Partien.

An anderen Stellen ist 2 war ebenfalls die durch die alveoläre Anordnung des Bindegewebes bedingte Struktur verwischt oder verschwunden, doch resultirt hier daraus keine bärtere und dunklere Beschaffenheil, sondern man bemerkt ein weicheres Gewebe etwa von der Consistenz einer Leber, leicht schneidbar und etwas heller grauweiss gefärbt. Diese Stellen sind es auch, in deren Nachbarschaft sich die ganz aufgelockerten, blutdurchsetzten Partien finden, und lassen durch ibre ganze Beschaffenheit schon von vornberein einen grösseren Zellreichthum erschliessen als die oben beschriebenen, die Hauptmasse des Tumors ausmachenden.

Das Bindegewebe sammelt sich an der Oberfäche zu einigen dichteren Zügen, welche den Vertiefungen $z$ wischen den oben erwähnten Höckern entsprechen. Von einer continuirlichen bindegewebigen Umbüllung (Kapselbildung) ist nirgends etwas zu seben; überall stösst man oberflächlich direct auf Tumormasse.

Nur an einer Stelle, entsprechend der Basis und Umgebung des kürzeren der beiden oben erwäbnten fingerförmigen Fortsätze, bemerkt man ausser der Tumormasse nebst einigen Gefässen geringen Calibers einige stark blutig suffundirte Muskelbündel. Dieselben bilden zum Theil eine compacte Masse, zum Theil werden sie durci schmale Tumorantheile auseinander gedrängt und rareficirt. 
Ausser diesen spärlichen Muskelbündein und Gerässeben findé sich aw Präparat kein an normale Organe oder Texturen erinnerndes Gewebe. Insbesondere ist zu erwäbnen, dass ron einer Unterkieferdrüse makrostropisch nicht eine Spur aufrufinden war. Da nun (wie bei Beschreibung der Operation erwähnt wurde) die ganze Gegend des normalen Standortes der Unterkieferdräse ausgeräumt und alles dort befindliche exstirpirt wurde, so erscheint der Sehluss gerechtfertigt, die Drüse sei in ibrer Iotalitat in dem sie substituirenden Tumor afgegangen.

\section{Nikroskopische Untersucbang.}

Von der trüharen Schnittfiache lässt sich mit dern Messer sehr spärlicher, fast wasserheller Saft abstreifen. Derselbe zeigt unter dem Mikroskope Zellen von der Grösse eines weissen Blutkörperchens bis weit darüber. Auch die Gestalt der Zellen wechselt von einer runden oder ovalen bis zu einer kurzspindeligen. Die Zellen besitzen einen nicht sebr breiten, ziexalich stark granulirten Protoplasmasaum, welcher einen relativ grossen, scharf abgegrenzten, kugel- bis oirunden Kern unschliesst. An vielen Zellen bemerkit nnan im Kern ein oder mebrere, stark Licht brechende Kernkörperchen.

Nach dieser mikroskopischen Untersuchung des frisch ansgestreiften Saftes wurden 6 Scheiben des Tumors aus den verschiedensten Theilen desselben in Müler'scher Flüssigkeit mit Formolzusatz fixirt, in Alkohol gehärtet, in Paraffin und in Celloidin theils zu einfacben, theils zu Seriensehnitten verarbeitet und in versehiedener Weise: mit Hämatoxylin und Eosin, Hämatoxylin-Säurefuchsin-Pikrinsäure (van Gieson), nach der Weigert'schen Fibrinfärbung und nit wässriger Thioninlösung gefärbt. Das Lrgebniss der mikroskopischen Unterstuchung an den gefärbten Schnitten war folgendes:

Wenn wir zunächst Schnitte aus der centralen grob-alveolären Hauptmasse des Tumors betrachten, so seben wir, dass den als schmale Septen schon makroskopiseh sichtbaren Gebilden schmälere und breitere Bindegewebszüge entsprechen. Dieses Bindegewebe ist durchgehends gefüssarm; der Zellgehalt wechselt. An manchen Stellen besitzt das Bindegewebe mässig zahlreiche Kerne und weicht von einem gewöhnlichen Bindegewebe nicht ab. An anderen Stellen fuden sich viel weniger Kerne. Da diese Stellen anch in anderer Beziehung bemerkenswerth sind, scllen sie sofort näher besprochen werden.

Wir sehen nebulich, während an den meisten Theilen der Septen das Bindegewebe deatlich fibrillären Bau mit verscbiedener Mächtigkeit der Fibrillen zeigt, an einigen, ganz regellos durch den Tumor vertheilten Stellen dasselbe mehr homogen werden, die Sonderung in Bundel verschwinden und gerade hier zugleich auch die Anzahl der Kerne abnebmen. Dieselben treten zuerst in grösseren Abständen als de norma von einander auf und verschwinden zum Schluss fast gänzlich.

Diesen Verschiedenheiten in der Struktur und Kernvertheilung entsprechen nun auch versehiedeno Tingibilitätsgrade. Bei der Färbung mit 
Hämatoxylin und Eosin erscheint das normale Bindegewebe rasa gefärbt, wobei feine Strukturdifferenzen sich auch durch feine Abstufungen im Farbenton kennzeichnen, bei der van Gieson'seben Färbung leuchtend roth, bei Thioninfärbung hellblau. Die erwähnten Stellen zeigten sich nun bei der ersten Färbung mebr hochroth und ohne jede feine Farbenabstufung gefärbt; nimmt die Veränderung sebr breite Bezirke ein (im mikroskopischen Sinne), so sieht man hie und da auch leicht bellbläulich-rosa gefärbte Stellen, deren Farbe ganz allmählich in die entsehieden sattrothe der Umgebung übergeht.

Bei Hämatoxylin-Säurefuchsin-Pikrinsäure-Färbung ist der Unterschied zwischen den fibrillären, kernreicheren und den homogenen, kernärmeren Partien kein so prägnanter, doch ist an letzteren Stellen das Roth ein deutlicheres und gemäss der grösseren Homogenität kein so leuchtendes. Den spärlichen bläulich-rosa Bezirken des Hämatoxylin-Eosin-Präparates entspricht hier eine ganz leicht blassblaue Tingirung, dabei mit einem Stich in's Gelbliche.

Bei Thioninfärbung erscheint das homogene Gewebe etwas dunkler als das de norma sich hellblau färbende Bindegewebe; doch ist die Differenz auch hier nieht so in die Angen springend wie bei Hämatoxylin-EosinTinction. Dagegen entsprechen den hellbläulich-rosa gefärbten Stellen hier Farbentöne, die zwar auch blau sind, aber eine, wenn auch leichte, so doch deutliche violette Nuance nicht verkennen lassen.

Zieben wir aus diesen Beobachtungen die Schlüsse, so müssen wir sagen, dass die Septen, welche die kleineren und grösseren Alveolen des centralen Haupttumors einschliessen, in ihrer grossen Mehrzahl von normalem Bindegewebe gebildet werden (Taf. II, Fig. 1a), dass aber an einigen, njcht näher zu bezeichnenden und ganz regellos zerstreuten Stellen das Bindegewebe die Charaktere der als hyalin bezeichneten Substanz annimmt und inmitten solcher Bezirke sich auch Andeutungen ron einer schleimigen (mucinösen, nicht myxomatösen) Beschaffenheit finden (Taf. II, Fig. 1a').

Die feinen Gefässe und Capillaren werden von diesen Veränderungen in ihrem Wesen nicht alterirt, man erkennt deutlich mit Endothelien ausgekleidete noch inmitten scbon ganz homogener, auch inmitten der schleimig sich nmwandelnden Bezirke.

Dies wäre über die Beschaffenheit der bindegewebigen Septen im centralen Bauptantheile des Tumors zu sagen. Bleiben wir zunächst bei diesem Theile überbaupt stehen und betrachten wir nun, was in den von jenen Septen umschlossenen Räumen, den grob-anatomisch wahrnehmbaren Alveolen, liegt - die eigentliche Tumorsubstanz.

Dieselbe ist zusammengesetzt aus Zellen und ans einer zu diesen in eigenthümlichen Beziehungen stehenden $Z$ wischensubstanz. Diese beiden Componenten füllen die von den bindegewebigen Septen offengelassenen Rảume complet aus. Blut- und gröbere Lymphgefässe fehlen. Nur an manchen Stellen zweigen von den peripherischen Septen feinste (makroskopisch eben nicht sichtbar gewesene) Züge in das Innere der Tumormasse hinein $a b$, von welchen späterhin noch die Rede sein wird. 
Fragen wir zunächst nach der Natur der zelligen Bestandtheile, so finden wir die Zellen von ziemlicher Grösse, derjenigen mittelgrosser Epithelien entsprechend, and grösstentheils rund oder elliptiseh contourirt. Ihre sonstige Beschaffenheit entspricht ganz der bei Besprechung des frischen Ausstreifpräparates gemachten Beschreibung: nicht sehr breiter, mit Eosin hellrosa färbbarer Protoplasmasaum, grosser, scharf contourirter, ${ }_{2}$ runder oder elliptischer, mit Hämatoxylin sich schön dunkelblau (nicht schwarzblau) färbender Kern. Bei der Färbung nach yan Gieson erscheint der Kern braun, das Protoplaswa hellgelblich; Thionin färbt die Kerne sattblau, das. Frotoplasma bellblau.

Diese Zellen, die also den Epitbelzellen nahe zu steben scheinen, (Taf. II, Fig, le), sind an manchen Stellen zu Haufen, Zügen und sonstigen Gruppen ohne irgendwie erkennbare Gesetzmässigkeit angeordnet; an den meisten Stellen aber wird ibre Gruppirung in charakteristischer Weise durch die eigenthümliche, sogleich zu besprechende $Z$ wischensubstanz beeinflusst.

Dieselue (Taf. II, Fig. 1 b) ist eine homogene Masse, im Allgemeinen gänzlich kernlos. Sie findet sich in verschiedener Mächtigkeit, bald auf dem Längssehnitt gesehen in schmalen Zügen von kaum doppelter Zellenbreite zwischen den Zellhaufen und -Reihen verlaufend, bald in dickeren Strängen dieselben auseinander drängend, bis zu dem Grade, dass an manchen Stellen das Gesichtsfeld fast vollständig von dieser Masse eingenommen wird und nur spärlieh von jhr tabrig gelassene Zwischenräume von Zellen erfüllt werden. Die letzteren finden sich dann ganz isolirt, eine in weiten Abständen von der anderen, eventuell durch Protoplasmaausläufer mit einander verbunden, wobei auch der Kern deformirt wird und seine runde ovale form in eine langgestreckte, spindelig verzogene verändert. Dieser Vorgang geht bis zum völligen Schwand der Zellen, so dass man Stellen findet, wo das Gewebe aus sich durcbkreuzenden und desbalb bald längs, bald quer, bald schief getroffenen derartigen Balken besteht. Dieselben sind auch bier meist homogen-hyalin, an manchen Stellen zeigen sie an Längssebnitten eine ganz leicht angedeutete Streifung, auf dem Querschnitt besonders in ihrer peripherischen Zone eine ebenso undeutliche concentrische Streifung.

Beachtenswerth ist nun das tinetorielle Verhaiten dieses Tumorantheiles. Dasselbe ist ein höchst variables. Im Allgemeinen färben sich die bomogenen Massea bei Hämatoxylin-Eosin-Färbung schön rosa, bei Färbung nach van Gieson leichtrosa, bei Thioninfärbung ganz bellblau. So verbält es sich zwar an der Mebrzahl der anzutrefienden. Stellen, aber ziernlich häufig begegnet uns ein anderes Verhalten, indem die fragliche Substanz sich mit der ersten Methode mehr violettrosa, mit der zweiten Methode hellviolett, mit der dritten hellbläulich-violett färbt. An noch anderen Stellen verschiebt sich das Verbältniss noch mehr; wir bekommen mit Hämatoxylin-Fosin oinen blänlich-violetten, mit Hämatoxylin-Säurefuchsin-Pikrinsäure einen hellvioletten Ton mit einem Stich in's Gelbliche, mit Thionin eine bellröthlichvioletite Farbe. 
Die Art der Vertheilung dieser verschiedenen Farbennüancen erscheint als eine ganz regellose, willkürliche. An räumlich von einander wenig entfernten und morphologisch scheinbar ganz identischen Stellen sieht man diesen Uebergang von rosa zu blau, von hellrosa zu hellgelblich-violett, von hellblau zu bellrotb eintreten. Damit soll nicht gesagt sein, dass derselbe unermittelt geschieht, denn zumeist geht die eine Farbe ganz allmählich in die andere über, dem Verhalten der Spectralfarben vergleichbar. Dies kann man besonders an vielen längsgetroffenen Balken beobachten, die in ihrem Verlauf bei immer gleichbleibender Struktur mehrmals die Farbe wechseln können. Nur wo zwei Balken neben einander verlaufen oder sich durchflechten, kann man an unmittelbar sich berührenden, eben nur durch den scharfen Contour des Balkens getrennten Stellen den plötzlichen Wechsel der Farbe wahrnehmen.

Ausser den bisher erwähnten Componenten im centralen Hauptantheil dieses Tumors, Zellen und homogener $Z$ wischensubstanz, findet sich aber noeh eine, auf den ersten Anblick von ihnen beiden sehr differente Art von Gebilden, ganz diffus zerstreut, bald mitten in Zellhaufen, bald einen homogenen Balken in seinem Verlauf unterbrechend, bald auch zu wehreren neben einander, oft so zahlreich, dass ebenso wie durch das oben beschriebene Verhalten der homogenen Balken an manchen Stellen, die Zellen entsprechend verdrängt werden und ähnliche Veränderungen, wie dort erwähnt, zeigen (Streckung, Compression, Veränderungen der Kerngestalt).

Es sind dies Hohlräume von stets runder oder ovaler Formation (Taf. II, Fig. 1d), deren Grösse von kaum doppelter Zellengrösse bis zum vielfachen derselben wechselt. Ihre Wandungen werden, wo sie inmitten melr bomogener Tumorpartien liegen, direct von der bomogenen Substanz gebildet; inmitten zelliger Partien wird die Wand von den Zellen geliefert, in wechselnder Anzahl und Anordnung. An vielen Stellen umsäumen dieselben die Lumina ganz regellos und in spärlicher Menge, so dass man den Eindruck eines zufälligen Nebeneinanders hat. An anderen Stellen aber formiren sich dio Zellen mehr cylindrisch oder eubisch und bilden einen scharf ansgeprägten und gut begrenzten Mantel um die Hohlräume, was der ganzen Formation ein drüsenähnliches Aussehen, etwa vergleichbar einer Schilddrüse, verbleibt.

Diese Hohlräume sind mit einer flüssigen Masse erfüllt, die in vivo einen verschiedenen Consistenzgrad gehabt haben mag. Man sieht nehmlich manche Lumina erfüllt von ganz gleichmässiger Masse, etwa ähnilich wie Schilddrüsencolloid in Struktur und Lichtbrechung (Taf. II, Fig. 1 d'), während in anderen ein Theil des Raumes ganz frei bleibt, da sich der entschieden dünnflüssige Inhalt bei der Härtung retrahirte, entweder in eine Ecke des Hoblraumes oder in mehrere und dann dieselben durch feine Streifen mit einander verbindend, dadurch merkwürdige sternförmige Formationen darbietend. In letzterem Falle hat der Inhalt ein feinpunktirtes Aussehen (Taf. II, Fig. 1d"), und das ganze äbnelt dann dem durch llärtung veränderten Inhalt von Lymphgefässen, feinkörnig geronnener Lymphe. 
Das tinctorielle Verhalten unserer Hohlräume ist aber ganz different von demjenigen der zum Vergleich herangezogenen normalen Gebilde; $a b$ dick- oder dünnflüssig, compact oder sternförmig, homogen oder feinkörnig, - der Inbalt aller dieser Räume ohne Ausnahme färbt sich mit HämatoxylinWosin dunkelblau, mit Hämatoxylin-Säurefuchsin-Pilarinsäure dunkelviolett, mit Thionin duvkelroth.

Durch ihre grosse Zahl, mannichfache Anordnung, verschiedene Grösse and eigenthümliche Färbung bringen aber diese soeben beschriebenen Gebilde in diesen sonst verbältnissmässig einfacb gebauten Tumorancheil grosse Abrechselung und gestalten stellenweise sein Aussehen zu einem sebr complicirten und fremdartigen.

Wir können also bis jetzt im Allgemeinen die Thatsache constatiren, dass der Tumor, abgesehen von den bindegewobigen Septen and abgesehen von den eben erwähnten eigenthümlichen Hohlräumen, aus zelligen und aus howogenen, hyalin-schleimigen Balken, welche beiden Balkensysteme sich in der mannichfaltigsten Weise durchflechten, aufgebaut ist. Demgemäss können wir den Tumor in diasem Antheil schon jetzt schlechtreg als Oylindrom bezeichnen.

Es handelt sich nun naturgemäss darum, in diesen complicirten Bau einiges Licht zu bringen und die Provenienz jedes einzelnen Bestandtheiles Aarzuthun. Am leichtesten fällt dies in Betreff des Stromas der Septen. Man kann sich leicht vorstellen, dass, gleichgültig wober der Tumor stamme, er die in der Nachbarschaft seiner Entstehung gelegenen Gewebsiücken zum Vordringen benutzte, in seinem Wachsthum hiebei durch die Umrandungen eben jener Lücken, also durch die bindegewebige Zäge, begreuzt und beengt. So sehen wir denn auch mitunter intnitten der Septen Bündel markhaltiger Nervenfasern, die einzelnen Faseru wohl erbalten, nur das Bündel in toto durch den Druck der Tumormassen auf den Quersehnitt deformirt, plattgedrückt, und hie und da die Fibrillen des Perineuriums auseinander gedrângt, um sindringenden Tumormassen zu weichen 1). Diese Beobnchtung reigt, dass wir die rein bindegewebigen Septen theils von schon vorber bestandenem, theils von neugebildetem Bindegewebe abuleiten haben.

Schwieriger schon ist die Provenienz der hyalin-schleimigen Zwischensubstanz im Tumor selbst (nach Struktur und tinctoriellem Verhalten muss zan ihr ja diese Doppelbezeichnung zu Theil werden Iassen) zu erklären. Im Allgemeinen sind Septen und Tumormasse von einander durch scharfe Grenzen geschieden. Sucht man jedoch genauer, so Jassen sich, und zwar besonders an Serienschnitten, feine Ausläufer erweisen, welche ron bindegewebigen Septen abzweigend in den Tumor einstrahlen und sich dort verzweigen. Zum Theil gehen diese Ausläufer von den als in hyaliner Degeneration begriffen beschriebenon Partien der Septa aus und vermitteln alsdann in ihren Endverzweigungen einen directen Uebergang rom bindegewebigen

1) Diese Beobachtung erklärt zum Theil gewiss die unerträghichen Schmerzen, welche Patientin bei leisester Berührung im Tumor empfand. 
Stroma zum bomogenen Balkenwerk (Taf. II, Fig. $1 b^{\prime}$ ). Oder es gehen von den Septen rein bindegewebige $Z$ äge $a b$; diese verfallen dann erst in ihrem weiteren Verlaufe der Degeneration, einmal mit directem Vorwiegen der hyalinen, ein andermal der schleimigen. Von irgend einem Zusammenhang mit den Gefässwänden konnte ich nirgends etwas sehen. Die an sich schon gefässarmen bindegewebigen Septen degeneriren in toto. Die fibrillären und byalinen Auslăufer sind bald gefäss-, bezw. capillarbaltig, bald sind sie es nicht. Nach alledem können wir die Genese der bomogenen, hyalinschleimigen $Z$ wischensubstanz, des die Zellen trennenden Balkenwerkes als eine bindegewebige bezeichnen und für dasselbe die gleiche Genese wie für die bindegewebigen Septen annehmen.

Betreffs der zelligen Theile des Tumors bemühte ich mich schon an diesen Punkten, ihrer Genese näher zu treten. Während ihr morphologisches Verhalten im frischen Ausstreif- und im Trockenpräparat einen deutlich epitbelialen Charakter documentirte, konnte ich mich trotzdem nicht sofort für eine epitheliale Genese entscheiden. Denn die Zellform allein ist für die stricte Bestimmung der Genese nicht ausschlaggebend, wie wir an so vielen grosszelligen Alveolarsarcomen, Endotbeliomen, Peritheliomen und anderen Tumoren sehen. Auch lag vorläufig nicht der geringste Anhaltspunkt vor, von welchem epithelialen Gebilde dieser Gegend eigentlich der Tumor, falls er wirklich epitbelialer Natur sei, abstammen solle; denn an den bis dabin untersuchten Präparaten fanden sich ausser den erwähnten Nervenfasern keinerlei an normale Organe erinnernde Gebilde. Wenn andererseits die stellenweise drüsenähnliche Anordnung der Zellen um schleimerfüllte Hohlräume von Neuem einè Abstammung von Epithelien nahelegte, so waren eben ähnliche Bildungen in entschieden sarcomatösen und endothelialen Tumoren längst beschrieben: auf der anderen Seite war die Durchflechtung der Zellen mit dem homogenen Ballsenwerk an vielen Stellen eine derart innige, dass man nicht ohne Weiteres die Annahme von der Hand weisen durfte, beide Componenten entstammten einem und demselben Generator: dem Bindegewebe. Vorläufig musste ich also die Frage nach der Pathogenese der zelligen Elemente noch offen lassen.

Was den vierten, letzten und sonderbarsten Componenten dieses Tumorantheiles, die Hohlräume betrifft, so konnte man vorläufig nur sagen, ihr Inhalt, ob dick- oder dünnflüssig, homogen oder feinlörnig, sei ein mucinreicher, weil sich dies aus den tinctoriellen Verhältnissen ergab. Bezüglich ihrer Genese aber entstanden die gleichen Schwierigkeiten wie bezüglich der Zellen. Es ergab sich ein Widerspruch zwiscben dem Vorkommen dieser drüsenähnlichen Bildungen innerbalb compacter Zellhaufen einerseits und innerbalb fast homogen-hyaliner, ganz zellenloser Antheile des Tumors andererseits. Auch über diese sehleimerfüllten Hohlränme musste ich also vorläufig mein Urtheil in suspenso lassen.

Wir verlassen daher diesen centralen Hauptantheil des Tumors und wenden uns denjenigen Partien zu, welche bei der grob-anatomischen Bệ. 
schreibung sich als weicher, beller grau und hie uad da aufgelockert und biutig imbibirt erwiesen. Die yod mir untersuchten derartigen Partien stammen aus dem längeren der beiden dem centralen Trumor aufsitzenden Fortsätze, welcher abgesehen von den sogleich zu besprechenden Partien, in allen Einzelheiten histologisch dem Centraltumor glich. Dieso Partien aber erwiesen sich als yorwiegend zelliger Natur. Auf weite Strecken bin, oft ein ganzes Gesichtsfeld occupirend, besteht hier der Tumor nur aus Zellen. Sie zeigen wieder eine sehr epithelähnliche Beschaffenheit und liegen obne jede Andeutung von Zwischensubstanz neben einander, Nur ganz spora. disch bomerkt man eine Art Stroma; an anderen Stellen ist dasselbe etwas reichlicher, zeigt aber hier weder fibrilläre, noch hyaline Beschaffenheit, sondern eine geradezu nyxomatöse: es bildet mit Hämatoxylin-Eosin bläulich sich färbende Züge und Inseln, in welchen spärliche Zellen von sternförmiger Gestalt, unter einander durch schmale Protoplasma-Fortsätze verbunden, angeordnet sind. Am Rande solcher Zellcompleze und sie einschliessend finden wir wieder fibrilläres Bindegewebe und wir sehen auch wieder wie oben betreffs der Genese der hyalin-schleimigen Balken, dass von diesen peripherischen Bindegewebe Züge in's Innere der Zellcomplexe abgehen, wobei dieselben sieb sofort in Sebleimgewebe unwandeln. Hier kann man übrigens auch sehen, wie das präexistirende Bindegewebe bei der Gestaltung des Tumors mitwirkt: man findet hier nehmlich Reste quer gestreifter Musculatur in den versebiedensten Stadien nond Formen der Zerstörung: Verschmälerung, hyaline Aufquellung, Verschwinden der Querstreifung, interstitielle Kernwucherung wechseln ganz regellos. Nun sieht man gerade hier, wie das Nuskelbindegewebe von ganz jungen Tumorzellbaufen durchsetzt wird (theilweise noch mit Erbaltenbjeiben einzolner Muskelfaserreste innerhalb der Zellcomplexe) und dabei die oben beschriebene myxomatöse Veränderung erleidet.

Das ganze macht den Bindruck einer in schrankenlosem Wachstbum und atgpischer Wucherung begrifenen carcinomatösen Geschwulst. Nur die myxomatösen Inseln und Züge bringen etwas Fremdartiges in das Bild; doch kommt Aebnliches ja bei vielen reinen Epitheliomen im Gesicht und am Gaumen vor.

An vielen anderen Stellen dieses Tumorantheiles finden wir die Struktur des Haupttumors wieder, aucb die beschriebenen eigeuthümlichen Hohlräume. Nur zeigen sich dieselben nicht an allen Stellen mit homogenem oder körnig geronnenem Schleim erfüllt, sondern mit rothen Blutkörperchen, theils isolirt, theils zu Gaufen zusammengeballt zum Theil auch schon verklumpt und mit gelbbraunem Blutpigment vermengt. Stellenweise füllt das Blut ganze solche Lumina aus und sammelt sich auch im hyalinen $Z$ wischengewebe an, die ohnedies spärlichen Zellen noch mehr verdrängend. Diese Stellen entsprechen also den makroskopisch röthlich gefärbten und aufgelockerten Partien.

Noch baben wir aber einer dritten Partie dieses Tumorantheiles zu gedenken. Dies sind ebenfalls Stellen, wo der Tumor scheinbar ganz jung in frischem Vordringen gegen seine Umgebung begriffen ist. Als solche 
figurirt auch hier die quergestreifte Musculatur der Balsmuskeln mit ibren bindegewebigen Hüllen und Septen. Die Jugend dieses Tumortheiles zeigt auch die starke kleinzellige Infiltration, welche stellenweise die bindegewebige Struktur der Umgebung fast verdeckt.

Diese bindegewebigen Septen selbst sind mässig zellreich, von deutlich fibrillärer Beschaffenbeit, nur stellenweise etwas mebr homogen, bäufig ron stark mucinbaltiger Lymphe durchtränkt, und demgemäss mit HämatoxylinEosin stark bläulicb gefärbt. Inmitten dieser theils normalen, theils ödematös-mucinös durchtränkten (njcht myxomatösen), theils stark kleinzellig infiltrirten Bindegewebsbündel finden sich, dieselben sowie die erbalten gebliebenen Huskelfasern auseinander drängend Haufen yon Zellen, welche einzeln, sowie in ihrer ganzen Anordnung betrachtet, wieder entschieden epithelialer Natur zu sein scbeinen. Sie sind sehr polymorph, zeigen cylindrische, cubische, ovale, runde, spindelige Formen, haben hier sehr reichliches, mit Eosin gut färbbares Protoplasma und grossen, runden, biäschenförmigen, mit Hämatoxylin sich schön blauviolett färbenden Kern. Sie liegen sehr häufig zu nur 8-10 beisammen, entweder als strukturloser Zellbaufen, oder aber jede einzelne cylindrisch oder cubisch geformt, scharf von einander abgegrenzt, zusammen ein Lumen einschliessend, welches je nach der Schnittrichtung bald rund, bald oval ist oder vollständig längsgetroffen, in welchem Fall dann die Zellen in je einer Reihe neben einander zu beiden Seiten der Lichtung, wieder schön eylindrisch oder cubisch, angeordnet sind. Der Inhalt dieser Schläuche wird ron einer glasigen oder feinkörnigen Masse gebildet, welche distincte Mucinreaction giebt (mit Hämatoxylin-Eosin dunkelblau, mit Thionin hochroth. Das ganze erinnert wieder in frappirender Weise an drüsenäbnliche Bildungen (Taf. II, Fig. 2 b), eigentlich an Schaltstücke oder kleinere Ausführungsgänge von Schleim- und Speicheldrüsen.

An anderen Punkten liegen diese Zellen nicht so spärlich, sondern in Zügen, Haufen, Strängen das Bindegewebe durchziehend; auch hier bewahren sie ihren epitheläbnlichen Charakter, das ganze gleicht dem Bilde von Krebszapfen ohne Verbornung und obne Krebsperlenbildung (Taf. II, Fig. 2). Nur tritt uns hier eine bedeutsame Brscheinung entgegen. Mitten in einem compacten Zellstrang siebt man hie und da eine Zelle in ihrem Contour undeutlich werden, bezw. den von einer Zolle einzunehmenden Platz durch eine bläuliche (mit Thionin röthliche) Masse ausgefüllt, gegen welche die sonst rosa gefärbten (mit Thionin blauen) Protoplasmaleiber der übrigen Tumorzellen scharf abstechen. Hie und da ist ein Kern oder sind Reste eines solchen in schleimiger Masse noch wahmehmbar (Taf. II, Fig. 2a'), in der weitaus grössten Ueberzahl aber schwinden diese vollständig und man siebt lediglich solche schleimerfüllte Lücken (Taf. II, Fig. 2 a) in den sonst ganz cowpacten Zellsträngen. Hand in Hand mit dem Kernschwund geht ein Grösserwerden der Hohlräume, vielleicht bedingt durch eine derartige Degeneration zweier oder mehrerer benachbarter Zellen, vielleicht auch durch Aufquellen einer einzigen. $Z u$ 
Eniseheiden ist dies nicht, da man meist sehon grössere, ganz scbleinerfüllte Hoblräume ohne Kem za Gesicht bekommt. Die Form derselben ist stets eine rundliche oder ovale, nie eine längliche oder gestreckte, so dass man auf eine Kugel- oder sphärische Form schliessen darf. Thre Grösse wechselt von etvas über Zellgrösse (an den Stellen, wo sie noch Kerne zeigen) bis zu einer derartigen, dass die zelligen Stränge zu einer einfachen oder doppelten Reihe von Zellen rareficirt werden. Auf Querschnitten von gerade an solchen Stellen getroffenen Zellsträngen siebt man dann einen doppelten oder gar einfachen Zellring, scharf abgegrenzt gegen das schleimhaltige Lumen. Es resultirt daraus wieder ein dem Ausseben der Schilddrüsentubuli, oder eines Speicheldrüsenansfährungsganges ähnliches Bild. Wo die Veränderung an mehreren von nur sebr spärlichem $Z$ wischengewebe 7 on einander geschiedenen, sebr nahe an einander liegenden Zellsträngen 70 sich geht, oder wo in einem sehr dicken Strange mehrere solche Hohlräume sich etablirt haben, oder auch wenn ein mehrfach gewundener Strang an mebreren Stellen, ron denen gerade eine jede solche einen Hohlraum aufweist, rom Schnitt getrofien wird, überall da ergaben sich Bilder, welche jenen Stellen des centralen Hanpttumors, bei deren Besprechung jene eigenthümlichen, von den übrigen Tumorbestandheilen scheinbar vollständig differenten schleimerfüllten Hoblräume erwähnt wurden, ausserordentlich ähnlich sind, bezw. vollständig identisch mit ibnen erscheinen.

Der centrale Tumortheil erweist sich nun, schon seiner Lage nach, ferner in seinem histologisehen Verbalten und dem Fehlen jeglichen Restes normaler Organe als der ältere Tumortheil; der die soeben beschriebenen Gebilde enthaltende Abschnitt dagegen erscheint seiner peripherischen Lage nach, ferner durch seine stark zellige Wucherung und insbesondere durch das sichtbare Vordringen in noch vorhandenenes normales Gewebe als weitaus jünger. Demgemäss is t die Ansicht nicht unberechtigt, dass, so wie der centrale Haupttumor nicht nur genetisch, sondern auch morphologisch das spätere Entwickelungsstadium darstelle, so anch wenigstens ein Theil jener Hohlräume des Centraltumors ans solchen degenerirenden, schleimig a fquellen. den Zellen entstebe, woourch ein Genese dieser schleimerfullten Hohl räume aus Zellen resultirt.

Für einen Theil dieser Hoblräume ist also diese Genese anzunehmen, für einen anderen werden wir bei Besprechung des dritten Tumorbaupttheiles zu einer anderen Genese geführt werden. - Ich muss noch bemerken, dass ich in diesem Antbeil auch Reste der Submaxillardräse antraf, von welchen später die Rede sein wird.

Wir wollen uns jetzt dew dritten Hauptheil des Tumors zuwenden. Wie erinnerlich, unterseheidet sich derselbe nur unwesentlich von der Hauptmasse des sonstigen Tumors; er ist nur härter, dunkler grau, bomogen in seiner Struktur, indem er keine Felderung durch bindegewebige Septen xeigt. Sehon makroskopisch schien or demnach lediglich aus knorpelähnlicher, 
"hyaliner" Substanz zn bestehen. Diese Vermuthung bestätigt sich denn auch im mikroskopischen Verhalten: das Hyalin bildet in der That die Hauptmasse dieses Tumortheiles. Wir sehen nehralich, wie in centralen Tumor an manchen schualen Septen, so hier an ganz compacten Massen, einen Uebergang von fibrillärem Bindegewebe in Hyalingebilde. Die Uebergänge finden vom Raude der zu besprechenden Tumorpartie nach dem Centrum graduell zunehmend statt. Das Bindegewebe wird immer kernärmer, zugleich verschwindet die hellirosa Farbe bei Hämatoxylin-Eosin-Tinction und die fibrilläre Beschaffenheit, bis zum Schluss das Ganze zu einer stellenweise völlig kernlosen, strukturlosen, homogenen, bei Hämatoxylin-Eosin-Färbung: hochrosarothen (nach van Giesen hellrosa, mit Thionin bellblauen) compacten Masse geworden ist. Hie und da zeigt sich in dieser noch eine Sonderung in sehr breite und sich durchflechtende Balken (äbnlich wie in den zelllosen Theilen des Centraltumors), an anderen Stellen zeigen sich spärliche Bindegewebskerne.

Wenn wir sagten, diese Masse bilde den Hauptbestandtheil dieser Tumorpartie, so ist damit nicbt gemeint, sie sei der einzige. Ws giebt anch hier einen zweiten Componenten, auch hier ist derselbe zelliger Natur, doch tritt er, verglichen mit dem centralen Haupttumor oder gar mit den zellreichen Partien des fingerförmigen Fortsatzes, gegen die anderen Componenten eben sehr zurück. Die Zellen erscheinen hier in den spärlichen, vom hyalinen Gewebe übrig gelassenen Lücken als durch die Härtung etwas von denselben retrabirte Zapfen von verschiedener, meist nur geringer Mächtigkeit. Auch hier sieht man inmitten compacter Schläuche einzelne oder mehrere Zellen undeutlich werden und verschleimen. Oefter aber biegen von compacten Strängen kleinere Ausläufer, aus wenigen hinter einander gereihten Zellen bestebend, in die compacte hyaline Masse ein, schnüren ein Stück derselben $a b$ und schliessen es in sich ein. So bekommt man Bilder, welche einem Harnkanälchen mit byalinem Cylinder morphologisch und auch tinctoriell nicht unäbnlich sind.

Nun ist aber das bomogene Gewebe nicht durchgebends Hyalin; wie am centralen Hauptumor, so sehen wir auch bier eine Aenderung des tinctoriellen Verbaltens eintreten. Wir bemerken Complexe, welche sich mit $\mathrm{Hä-}$ matoxylin-Eosin blau, mit Thionin roth färben, also wieder als schleimig zu erkennen geben. Die meisten dieser Stellen zeigten keine scharfe Abgrenzung gegen die hyalinen Partien. Nun kann es rorkommen, dass die Abschnürung eines Stückes der compacten Umbüllung durch eine von einem Zellstrang abzweigende Zellreihe gerade an einer solchen schleimigen Stelle geschieht, woraus sich Bilder ergeben, wo einer tubulösen Drüse ähnlich gruppirte Zellen ein schleimerfülites Lumen umgeben: und nun haben wir eine Erklärung für einen Theil der drüsenähnlichen Bildungen, nehmlich ibre Entstehung durch Einwachsen von Zellen in schleimig umgewandeltes Bindegewebe, also nur ein späteres Stadium der vorhin beschriebenen harnkanälchenäbnlichen Formation.

Oder aber wir sehen die Aenderung des tinctoriellen Verhaltens ganz 
abrupt, scharf abgegreant eintreten. Sie gebt dann auch morphologiseh weiter, indew nicht wie früber das Gewebe seine homogene Strulatur beibehält, sondern geradezu verflüssigt wird. Dann zieht sich die schleimige Elüssigkeit, compact oder feinkönig geronnen, von der eine mehr oder weniger scharfe Grenze, meist einen kreisförmigen Contour bildenden hyalinen Umbïllung zurück.

Die daraus resultirenden Bilder gleichen dann vollständig jenen, welche wir bei Besprechung des Hauptiumors als schleimerfüllte Hohlräume innerbalb zellarmen oder zellenlosen byalinen Balkenwerkes geschildert baben. Für diese letzteren wussten wir, in Gegensatz zu den innerhalb zellieicher Complexe gelegenen and unserer Annatme nach der Umwadiung von Zellen ibren Ursprung verdankenden Hoblräumen, eine Erklärung schuldig bleiben. Wir glauben dieselbe jetzt gebeu zu fönnen, indem wir dieselben also von multipler circumscripter schleimiger Umwandlung bomogener compacter Masse herleiten.

Damit hätten wir die rein morphologische Untersuchung der verschiedenen Theile dieses Tumors abgeschlossen, auf Grund welcher wir uns berechtigt erachten, in der Hauptsache dem Tumor die Diagnose "Cylindrom" zuzuerkennen. Zugleich sind wir bereits bei dieser Gelegenheit zu aus unseren morphologischen Beobachtungen zu folgernden Schlüssen in Betreff der genetischen Verhältnisse einiger Componenten dieses Tumors gelangt. Fassen wir diese bis jetzt erworbenen Beobachtungen und Annahmen zusammen, so ergiebt sich bezüglich der einzelnen Componenten kurz Folgendes.

Der Tumor besteht 1) aus faserigem Bindogewebe, welches die gröberen Septen, 2) aus epithelähnlichen Zellen, welche stellenweise die Hauptmasse des Tumors, 3) aus hyalin-schleimigem Balkenwerk, welches ebenfalls stellenweise die Hauptmasse, an anderen Orten einen charakteristischen Bestandtheil liefert, und 4) aus eigenthümlichen, diffus und regellos vertheilten, schleimerfüllten Hohlräumen.

Was die erste Componente betrifft, so haben wir deren Hervorgehen aus Bindegew ebe, theils priexistirendem, theils neugebildetem, bereits dargethan.

Was die hyalin-schleimige, so charakteristische und stellenweise schon makroskopisch dem Ganzen ihr Gepräge aufdrückende Substanz anbelangt, so konnten wir an allen ihren Standorten ihre Zugehörigkeit zum Bindegewebe und ihre Abstammung von diesem beobachten. 
Betreffs der Genese der eigenthümlichen Hohlraumbildungen sind wir ebenfalls zu folgenden definitiven Resultaten gekommen. Ein Theil von ihnen ist Zellprodukt, indem er einer Metamorphose der zelligen Elemente des Tumors (Aufquellung mit Kernschwund und Verschleimung, Auseinanderdrängen der Nachbarzellen) seine Entstehung verdankt.

Ein anderer Theil, und zwar wahrscheinlich der vorwiegende, ist dagegen bindegewebiger Genese, und dies in verschiedener Weise. Einmal durch directe circumscripte schleimige Umwandlung hyaliner Substanz, die bis zur Erweichung und Verflüssigung geht; oder durch Abschnürung schleimig sich umwandelnder Theile von hyaliner Grundsubstanz durch in dieselbe eindringende Ausläufer von Zellsträngen, welche um die abgeschnürten Theile zellige Mäntel bilden.

Wir haben also von den bis nun besprochenen Gebilden den grössten Theil als genetisch mit dem Bindegewebe zusammenhängend gefunden, nur einen kleinen Bruchtheil mit den zelligen Elementen in Beziehung gebracht. Auf diese letzteren concentrirt sich nun unser Hauptinteresse, und wir trachten nun, ihrer Genese näher zu treten.

Aus morphologischen Merkmalen, nehmlich aus der epithelähnlichen Gestalt der Zellen, sowie aus den häufig vorkommenden drüsenähnlichen Formationen ohne weiteres auf eine epitheliale Genese zu schliessen, ist ja unstatthaft. Andererseits den Ausgangspunkt der zelligen Wucherung aus Mangel an directen Beweisen für die epitheliale Genese in's Bindegewebe oder die Endothelien zu versetzen, geht auch nicht an; denn positive Beweise hiefür sind ja nicht vorhanden, und auch das epithelähnliche Aussehen und die drüsenförmige Anordnung der Zellen spricht dagegen.

Um die Abstammung der Zellen dreht sich aber zugleich die Frage nach der eigentlichen Natur des ganzen Tumors. Denn von allen seinen Componenten bilden die zelligen Theile das hauptsä.chlich Active; dies wird, ausser durch das Vorhandensein wenn auch spärlicher Mitosen, bewiesen durch das directe Vordringen zelliger Gebilde in die intacte Umgebung und die prompte Reaction der letzteren: Kleinzellige Infiltration. 
Von epithelialen Gebilden, die dem Tumor als Ausgangspunkt dienen konnten, kam hier ausser der Haut, welche aber aach klinischen Angaben intact über den Tumor hinwegzog, nue die Glandula submaxillaris in Betracht. Makroskopisch war aber in dem exstirpirten Präparat nichts von ihr zu sehen. Auch mikroskopisch suchte ich lange vergebens nach Resten von ihr, bis ich deren endlich doch fand, und zwar an einer Stelle an dem fingerförmigen Fortsatz des Haupttumors, ebenda wo auch quergestreifte Musculatur in verschiedenen Stadien der Zerstörung; veranlasst durch das Fordringen von jungen Tumorzellen, von uns gefunden wurde. Wir betonten schon, dass wir diese Partien für die jüngsten halten, und sehen nun auch an der Drüse analoge Vorgänge sich abspielen, wie an der quergestreiften Musculatur.

Die Drüse, oder besser gesagt ihre Reste, sind weit auseinander geworfen durch vordringende Tumormasson. Meist bieten diese letzteren das Bild zelliger Zapfen dar, entweder ganz compact oder die oft erwähnten, kleineren oder grösseren, mit Schleim oder Hyalin erfüllten Hoblräume zeigend. Meist gelangen diese Stränge in geschlossener Masse an irgend eine Gruppe von Drüsenacinis heran. Die Zellstränge senken sich nun in Form eines gegen diese Gruppen von Acinis convexen Buckels in dieselbe ein. Der Körper dieses Buckels wird von den Tumorgebilden geliefert, seine Begrenzung bildet das Bindegewebe der Drüse, und zwar zunächst in Form eines dichteren Bindegewebswalles oder eines gröberen Gefässes, sodann immer schmäler werdend, bis zum Schluss nur mehr eine lang ausgezogene Bindegewebsfaser mit spindeligem, stark tingirten Kern oder ein feinstes Capillargefäss die Grenze zwischen Tumor und Acinus bildet. Derr Effekt dieses activen Andrängens der Zellzapfen gegen die präexistirenden Gewebe äussert sich aber nicht nur am Bindegewebe und den Gefassen, sondern auch am Drüsenparenohym. In dem Maasse nebmlich, als die Scheidewand verschmälert wird, verfällt arch der Acinus, oder eine ganze Gruppe von solchen dem Schwund, der reinen Atrophie. Der Kern der einzelnen ihn zasammensetzenden Zellen bleibt zwar bis zum Schluss deutlich und tingirt sich etwas stärker als de norma, aber das Protoplasma schwindet, so 
dass ein Acinus successive auf die Hälfte, ein Drittel, Fünftel u. s. w. seines ursprünglichen Volumens gebracht wird und schliesslich eine ganze Gruppe von Acinis sich nur als neben einander verlaufende, auf's Höchste comprimirte, mit stark gefärbten Kernen versehene, schmale Zellreihen präsentiren. Während dieses ganzen Vorganges bleibt aber, wie erwähnt, der eigentliche Tumor von den Parenchymresten durch einen, wenn auch noch so schmalen Bindegewebsrest oder eine, wenn auch stark comprimirte Capillare streng geschieden; nie kommt es also zu einem directen Hineinwachsen von Tumorzellen in atrophirende Drüsenacini, sondern erst wenn letztere vollständig verschwu uden und nicht einmal mehr in Form von schmalen Kernreihen angedeutet sind, nehmen Tumormassen ihren Platz ein.

Da erschien es mir nun von höchstem Belang, dass ich in diesen Partien hie und da auch folgende abweichenden Bilder sah. Es giebt nehmlich auch noch relativ intacte Drüsenantheile, mit normal grossen Acinis in den bekannten verschiedenen Secretionsphasen der Speicheldrüsen. Die Drüsenepithelien präsentirten sich hier vollständig intact mit scharf von einander geschiedenen Contouren, granulirtem Protoplasma und bläschenförmigem, schön blau sich färbenden Kern. An 5 oder 6 Stellen sah ich nun in unmittelbarer Nachbarschaft solcher normaler Acini, ihnen direct angelagert, ohne jegliche Andeutung einer trennenden Bindegewebsfaser oder Capillare, und ohne auf die Acini irgend welchen sichtbaren Compressionseffekt auszü̈ben, deutliche Tumormassen. An der Gruppirung zu einem vielzelligen Strang, jede Zelle mit schwarzblau gefärbtem Kern und spärlichem Protoplasma, waren diese Gebilde als Tumormasse kenntlich, besonders aber durch das Vorhandensein kleinster, kaum über zellgrosser Lücken, erfüllt mit dem schon oft erwähnten hellbläulichen Schleim und eventuell einem bis zwei undeutlichen, verschwommenen Kernen.

Wollte man nun annehmen, dass es sich auch an diesen Stellen um nichts Anderes handle, als um ein Vordringen von Tumormassen gegen eben noch intacte 
Drüsenacini, so wäre dem das Verhalten der übrigen, vom Tumor durchwoherten Drüsentheile entgegeazuhalten: denn überall, wo sonst noch intacte Acini und etwa zugleich Tumormassen in ihrer Nachbarschaft sich finden, sehen wir dieselben, wie erwähnt, durch mehrere Lagen von Bindegewebsfasern, also eine dicke Trennungsschicht, von einander abgegrenzt. Wo aber andererseits Tumor and Drüsenreste in so nahe Beziehung treten, sehen wir die letzteren stets atrophiren and sogar zum volligen schwund kommen, bevor an ihren Platz Tumormassen gelangt sind; so lange nur eine Spur von, wenn auch noch so atrophischer Drüsensubstanz vorhanden ist, vermisst man nirgends ein deutliches, wenn auch zartes, trennendes Gebilde - wie dies ja auch schon erwăhnt wurde.

Ich schliesse daraus, dass es sich bei der zuletzt beschriebenen Veränderung am nichts Anderes handle, als um wenige, noch erhalten gebliobene Ursprungs. punkte des Tumors. Die vielen anderen derartigen Ausgangspunkte desselben sind eben seinem schrankenlosen Wachsthum zum Opfer gefallen, und die wenigen erhalten gebliebenen finden sich ja anch an Stellen, welche wir als die jüngsten und peripherischsten des ganzen Tumors erkannt haben.

Damit wären wir nun auch zu einer definitiven Ansicht uber die Genese des vierten und wichtigsten Tumorbestandtheiles, der epithelähnlichen Zellen und der von ihnen zum Theil abstammenden Hohlräume gekommen und vindiciren den Zellen des Tumors eine directe Abstammung ron den Drüsenalveolarepithelien.

Toh halte also den Tumor für einen epithelialen, für ein Carcinom. In diesem Fall kommt aber vicht, wie gewöhnlich, durch Bildung solider Zellmassen ein Drüsenkrebs oder Markschwamm, sondern durch das eigenthümliche Verhalten der Zellen sowohl, als auch durch die Veränderungen des Bindegewebes ein Tumor zu Stande, welchen man, wie dies $j a$ in ähnlichen, allerdings andere Organe betreffenden Fiallen von anderen Autoren schon geschehen ist, als Carcinoma cylindromatos am oder Cylindroma carcinomatosum bezeichnen kann. Durch diese Bezeichnung wäre alsdann 
das morphologische, wie das histogenetische Verhalten dieses Tumors zum Ausdruck gebracht.

II. Th. H., 52 Jahre alt, Hutmachersgattin, wurde am 3. December 1896 anf die Klinik Gussenbauer aufgenommen (Z. 16, Prot. No. 364).

Die Anamnese ergiebt: Vater der Patientin ist an Herzschlag, Mutter an Herzwassersucht gestorben. Von 3 Geschwistern starben 2 an unbekannter Krankheit, eine Schwester lebt. Patientin hat im Alter von 4 Jahren an Nervenfieber gelitten, sonst war sie stets gesund. Sie bekam mit $15 \mathrm{Jah}-$ ren die Menses, die sie erst im Alter von 51 Jahren verlor. Sie ist seit 26. Jahren verheirathet, bat sechsmal geboren und einmal abortirt. Zwei Kinder starben an den Folgen der schweren Entbindungen, eines 16 Wochen alt lungenkrank, drei leben und sind gesund.

Vor 8 Jabren litt Patientin an Zahnschmerzen im rechten Unterkiefer, wobei auch die Drüsen an der rechten Halsseite nahe dem Unterkiefer angeschwollen waren.

Vor 4 Jahren, als sie abermals an Zahnweh litt, bemerkte sie einen mandelkerngrossen, derben, barten Knoton über dem rechtem Interkieferaste, der ibr jedoch keine Beschwerden verursachte. Er nahm allmählich an Grösse zu, soll jedoch seit $\frac{1}{2} \mathrm{Jahr}$ etwas kleiner geworden sein (!). Seit zwei Monaten ist Patientin durch brennende Schmerzen gequält, welche vorwiegend die Zungenspitze befallen und sich von da auf den Mundboden, den rechten Arcus palato-glossus und den weichen Gaumen erstrecken. Druck auf die vergrösserte Glandula submaxillaris ruft die Schmerzempfindungen hervor, bezw. steigert die vorhandenen. Zur Zeit der Parästhesien ist die Geschmacksempfindung an der vorderen Seite der Zunge für saure, süsse, gesalzene Speisen herabgesetzt oder aufgehoben. Ausserdem klagt Patientin über Gefühl von Trockenbeit in der rechten Mundseite. Die rechte Caruncula sublingualis ist gegenüber der linken verkümmert. Zeitweilig bestehen auch ausstrablende Schmerzen in der rechten Scbläfe und im rechten Obr.

Die Gegend der rechten Submaxillardrüse erscheint als Geschwulst von der Grösse eines Hühnereies, von unregelmässiger Gestalt, so dass der breitere Pol der Geschwulst unter dem Unterkiefer aussen am Halse, der schmälere, mebr zugespitzte am Boden der Mundhöhle zu tasten ist. Die Geschwulst umgreift so den rechten Unterkieferast, ist aber frei beweglich und nirgends mit der Umgebung verwachsen. Sie ist von weicher, elastischer Consistenz.

Klinisebe Diagnose: Carcinom der Glandula submaxillaris.

Therapie: 7. December Operation (Prof. Gussenbauer) in gemischter Narkose. Schnitt durch die Hant, das Platysma, die Fascia colli $2 \mathrm{~cm}$ unter dem rechten Unterkiefer und parallel mit diesem etwa $8 \mathrm{~cm}$ lang. Der Tumor wird exstirpirt, dabei auch ein Theil der Schleimbaut der Mundhöble entfernt und mehrere Ligaturen angelegt. Wegen der starken Spannung konnte die Mucosa oris nicht genäht werden. Seidenknopfnähte der Baut. Jodoformgaze-Contentiv-Verband. (Daver der Operation $\frac{1}{2}$ Stunde.) 
Gurgelwasser: Kali chlorieum.

12. December Yerbandwechsel, Erneuerung des Tampous, geringe Secretion.

14. December Verbandwechsel, Entfernung der Năhte, geringe Secretion.

17. December Verbandwechsel, Nabt reactionslos. Entfernung des Tampons. Geringe eitrige Secretion. Axswischen der Wunde mit Carboltuptern. Eufiuhrung eines frischen Tampons. Flanellbindenverband.

21. December geheilt entlassen.

\section{Pabologisch-anatomischer Befund.}

Das in meine Hände gelangte Präparat stellt einen Tumor won etwas unter Hühnereigrösse, röthlich-grauer Farbe, wechselnder soustiger Beschaffenbeit dar. An manchen Stellen ist seine Oberfäcbe glatt, an anderen fein-, an anderen grobhöckerig. Auf Durchschnitten erkennt man bald Stellen mit homogenem Gefüge, bald solche mit klein- und grossalveolärem Bau (wie beim ersten Tumor bedingt durch Ineinandergreifon weisslich glänzender Septen und homogener, röthlich-grauer Tumormasse) - alle diese Theile ron bedeutender, oft knorpelharter Consistenz, andere Theile dagegen viel weicher. Die Beschaffenheit ist eine sehr wechselnde, dieser Wechsel erfolgt bald übergangsweise, bald sehr abrupt.

Den Tumormassen hängen in ihrer Peripherie ziemlich beträchtliche Mengen von Fettläppchen, einige kleine Gefässe, ein etwa $1 \mathrm{ccm}$ messendes Stücls quergestreifter Musculatur, sowie noch mehrere andere kleinere musculose Theile an; ferner finden sich an 2 oder 3 Stellen Gebilde, welche sich durch ihre rothbraune Farbe, weiche Consistenz und regelmässigen Aufbau vom Tumor sowohl, wie auch von der quergestreiften Musculatur ziemlich scharf abgrenzen, die aber wegen ihrer Kleinheit (sie sind kaum erbsengross) nicht obne weiteres makroskopisch zu classificiren sind und nur vermuthungsweise als Theile der Submaxillardräse voriäufig bezeicbnet werden lronuten.

\section{Mikrosinopisebe Untersuchung.}

Die Untersuchng des spärlich abstreitharen Sâtes von der frischen Schnitflache ergab a ceb hier weder ganz analoge Zellformen wie im ersten Falle: mässig grosse Zellen mit relativ spär lichem Protoplasma, grossem bläschenförmigem, scharf abgegrenztem Kern und 1-2 stark lichtbrechenden Kerakörpercben, so cass wieder die Annabme einer epithelialen Geschwulst nabegelegt wurde.

Die genaue mikroskopische Untersuchung (ausgefüht nach ganz gleichen Methoden der Fixirung, Härtung, Einbettung und Färbung wie im ersten Falle) ergab nun ganz äbnliche worphologische Verhälnisse wie im Fall I.

Der Tumorbestehtaus bindegewebigen Septen, homogenem, hyalin-schleimigem Balkenwerk, epithelähnlichen Zellen und schleimerfüllten Hohlräumen in wechselnder Yermischung und mit wechselnder Prävalenz bald der einen, bald der anderen Componente. Auch hier waren die Schwierigkeiten botreffs der Frage nach der Gonese in Bezug 


\section{3}

auf 3 dieser 4 Componenten bald gelöst. Man sah das Vordringen des Tumors gegen seine Umgebung, besonders gegen die Musculatur und konnte Septirung in einzelne Lappen und Läppchen durch gröbere Bindegewebsfasern und feinere Fibrillen constatiren. Man sab dieselben sich in den Tumor einsenken und dabei direct der hyalinen ader schleimigen Degeneration verfallen, kennbar an dem genugsam erörterten strukturellen und besonders tinctoriellen Verhalten. Man sah wieder ganz diffus homogene Pairtien mit schleimiger Einschmelzung und partieller circumscripter Verflüssigung, wodurch ein Theil der eigenthümlichen schleimerfüllten Hohlränme in seiner Genese aufgeklärt war. Man sah ferner wieder die schleimige Umwandlung der Zelleiber mit Kernsehwund mitten in sonst compacten Zellzapfen, ibre zunehmende Aufquellung mit Compression der Nachbarzellen, so dass auch hier wieder ein Gitterwerk weiter, schleimerfüllter Lacunen mit spärlichen, trennenden Zellzapfen sich ergab, also die Erklärung dieser Hoblräume auf mehrfache Weise möglich war.

Auch die Zellen waren denen des ersten Falles nach Struktur im Einzelnen und Varietät der Anordnung im Allgemeinen ganz ähnlich. Im Einzelnen entsprachen sie dem Bild des Ausstreifpräparates als epithelähnliche Zellen; in Bezug auf ihre Anordnung sah man sie wieder zu Zapfen gruppirt, welche solid oder mit schleim- oder byalinerfüllten Hohlräumen versehen waren. Die Entstehung letzterer eriklärte sich wieder durch Degeneration und Aufquellung einzelner oder mehrerer Zellen, oder durch Abschnürung und Einschliessung von Theilen des hyalinen Balkenwerks durch kleine Zellstränge. Daraus ergaben sich also drüsenähnliche Bilder, deren Erklärung mit der entsprechenden im 1. Falle identiseh ist.

An manchen Stellen prävalirt auch hier weitaus das massige hyaline Balkenwerk gegenüber den hier weit auseinander gedrängten spärlichen Zellen.

Die Ableitung dieser verschiedenartigen zelligen Bildungen auf die einfachste unter ihnen, den soliden Zellzapfen, ferner diejenige der vorher besprochenen Gebilde auf das Bindegewebe, die passive Rolle der letzteren, die active der ersteren, die Classificirung des Tumors als Cylindrom schlechtweg standen also bald fost. Es ergab sich nur wieder die gleiche Schwierigkeit in der Beantworlung der Frage nach der Genese der zelligen Theile. Auch hier fonnte man nicht direct aus Morphologie und Anordnung aufepitheliale Genese schliessen, sondern war wieder eine solche erst zu suchen gezwungen.

Da ich aber in diesem Falle Theile der Submaxillaris sebon makroskopisch mit Wahrscheinlichkeit vermuthen und erblicken konnte, war mir mein weiterer Weg vorgezeichnet, und ich untersuchte nun an Schnitten lückenloser Serien sämmtliche derartigen in Betracht kommenden Anbängsel des Tumors. Dieselben erwiesen sich in der That als Drüsentheile. Theils waren sie auf weite Strecken hin rollständig normal, was schon einen Unterschied gegen den 1. Fall bedeutet; ganze Gesichtsfelder, ja ganze Serien boten das Bild gesunder Submaxillardrüse - theils waren sie in verschiedener Weise pathologisch verändert. 
Es fauden sich nehmlich auch Partien, welche den krankhaft veränderten Drüsentheilen des I. Falles glichen; dieselben boten demgemäss das Bild einer regellosen Durchwucherung des Drüsenparenchyms durch vordringenden Tu wor. Wieder sah man die Verdrängungserscheinungen, das Vordringen von soliden oder mit Hoblräumen erfüllten Tumormassen in Form sonvexer Buckel gegen das langsam der Atrophie anheimfallende Drüsenparenehyr, wobei ganz wie iruher das die Drüsonacini umspinnende Bindegewebe und die Gefässe länger persistiren, als das Drüsenparenchym; daber sehen wir auch bier wieder allerorten die scharfe Trennung von Tumor und Drüse bis zum völligen Schwund der letzteren. Díe eben besprochenen Partien gehen ganz allmäblich in normale äber, was eben dem schrittweisen Vordringen des Tumors entspricht. Hie und $d a$ werden die vordringenden Tumorzäge vor einer kleinzelligen Infiltration begleitet, die an manchen Stellen bis zur Einschmelzung des präexistirenden Gewebes führt, so dass hier Zellzapien ganz frei inmitten der Leukocytenunasse zu. liegen scheinen.

Bei genauerer Durchsicht der scheinbar normalen Drüsenpartien a ahm man nun aber auch hler, auf den ersten Anblick anscheinend ganz regellos mitten im Parenchym $A$ nsammlungen von Leukocyten wahr. Diese Infiltrationen folgten nan nicht etwa den Blutoder gröberen Lymphgefïssen, sondern liessen sich stets in evidente Beziehung zu Drüsenausführungsgängen briagen. An Serienschnitten sah man neholieb das Infiltrat entlang den grösseren, meist den gröbsten Ausführungsgängen fortkriechen. Die Leukocyten bilden um die Gänge einen breiten, ringförmigen Wall, oder auch eine Ansammlung auf der einen Seite derselben. Eine bestimmte bistologische Grenze fïr die Ausdehnung dieser ring- oder strangförmigen Infiltrate lässt sich nicht angeben. Ist am Schnitt der Gang quergetrofen, so grenzen sich die Infiltrate mit nicht immer gleich bleibender Schärfe geger die einfach bindegewebige oder drüsige Ungebung ab. Verfolgt man solche Querschnittsbilder durch ganze Serlen, so kann man auch die Irfiltrate, bisweilen dureh $30-40$ Schnitte, den gleichen Austührungsgang begleiten seben. Sie sind hiebei von den gröbsten Ausfübrungsgängen angefangen in der ganzen Längsausdehnung des secernirenden Systems continuirlich längs der Speicbelröbren und der Schaltstäcke, ja mitunter bis mitten in das die einzelnen Drüsenalveolen trenmende spärliche Bindegewebe verfolgbar.

Dieser Befund batte etwas angemein Charakteristisches und war sehr auffällig inmitten dieser sonst ganz und gar intacten Drüsentheile. Es Iag sehr nahe, in den von diesen Infiltraten betroffenen Bezirken der seheinbar normalen Dräse am Parencbym Abnormitäten zu vermuthen, welche nur auf den ersten Blick nicht offen zu Tage liegen vussten. Daraufhin untersuchte ich nun auf Seriensehnitten alle derartigea Infiltrate, deren ich ansichtig werden konnte, ferner die epithelialen Gebilde zwischen thnen und um sie herum, also in erster Linie die Ausführungsgänge. 
Dabei stellte sich's zunächst heraus, dass die Infiltrate ibre grösste Breitenausdehnung und ihre grösste Intensität stets an mittelgrossen oder grösseren Ausführungsgăngen haben; sie nehmen von da gegen beide Seiten des secernirenden Parenchyms, also insbesondere gegen das eigentliche Drüsenparenchym stets an Intensität ab. Die eigentlichen Drüsenacini oder -Alveolen waren dena auch überall, aucb an den spärlichen infiltrirten Stellen, in jeder Beziehung vollständig normal, abgeseben von hie und da constatirbarer Hypersecretion eines zähigen, glasigen Schleims.

Dagegen fanden sich sebr aufallende Veränderungen an den Ausfübrungsgängen gröberen und feineren Calibers, welche im infiltrirten Gewebe lagern. Onter 9-10 genau studirten und auf Schnittserien verfolgten derartigen Infiltrationen konnte ich diese Veränderung an den Speichelgängen in wechselnder Intensität 5-6 mal, also in über der Hälfte der Beobachtungen, feststellen, besonders deutlich an folgender, sogleich genauer zu beschreibender Stelle.

Wir verfolgen an einer Serie hinter einander folgender Querschnitte einen Ausführungsgang sehr groben Calibers. In seiner ganzen bis nun verfolgten Ausdehnung zeigte derselbe normales Verhalten: seine epitheliale Auskleidung ist (Taf. II, Fig. 3 a), wie es diesem grossen Caliber entspricht, eine deutlich zweischichtige und besteht aus bohen, von einander und vom Lumen deutlich abgegrenzten Cylinderepithelien mit grossem, ovalem, mehr peripherisch, d. b. vom Lumen abgelegenen Kern. Das Lumen ist, einer fast reinen Querschnittsrichtung entsprechend, ganz leicht elliptisch, fast kreisrund; leer oder mit Schleim erfüllt. - Nachdem man diese Verhältnisse in stets gleich bleibender Weise durch 20-25 Einzelschnitte hindurch constatiren konnte, bemerkt man nun auf einem Schnitt an einer Stelle der Wand dieses Ausfübrungsganges eine kolbige Verdickung derselben an ihrer Aussenseite; diese Verdickung bestebt aus einer grösseren Menge von Epithelien, welche ein Vielsehichtigwerden der epithelialen Auskleidung vortäuschen. Das Lumen bleibt dabei ganz regelmässig oval; der Zellhaufen ist solid.

Dies Bild hat bei dem Umstand, dass der Schnitt nicht rein quer geführt ist, an sich allein noch keine Bedeutung. Geht man aber successive zu den nächsten Schnitten, so siebt man den Zellhaufen nicht kleiner werden und versehwinden, soncern immer mehr wachsen. Er bleibt zunächst noch solid, am 3. oder 4. folgenden Sehnitt aber erhält er ein Lumen dadurch, dass sich die ihn zusammensetzenden Zellen wieder in schöner Regularität zweischichtig und cylindrisch gruppirten. An einem dieser Schnitte lässt sich das continuirliche Einmünden dieses Lumens in das Hauptlumen des Speichelganges mit Sicherheit feststellen.

Man bönnte also aus den bis jetzt beobachteten Bildern den Eindruck empfangen, als habe sich bei der Härtung oder sonstwie der betreffende Ausführungsgang an einer Stelle seiner Wand in toto gefaltet, und die Bilder seien nicht anders als durch in verschiedenen Niveaux und in verschiedenem Sinne erfolgte Kappschnitte zu Stande gekommen. Daran wäre allerdings 
nur dann festzuhalten, wenn auch in den folgenden Schniten das Lumen der Ausbuchtung mit dem Hauptlumen in Verbindung bliebe, oder wenn dasselbe mit den umsäumenden Zellen ebenso gradatim, wie wir es erscheinen sahen, anch wieder verschwände. Dem ist aber nicht so.

Gleich in dem nächsten Schnitte (Taf. II, Fig. 3 b) nach jenem, in welchem man den continuirlichen Zusammenbang beider Luwina, sowie dez ithrer begrenzenden Epithelien sab, ist von dem Lumen der Ansbuchtung überhanpt nichts mehr da. Dagegen existiren noch die vorher das Lumen einschliessenden Epithelien, aber nicht cylindrisch geformt und regulär im Kreise gestellt, sondern äusserst polymorph und ohne irgendwie zu dentende typische Anordnung. Diess so verschieden gefomten Zellen bilden nun insgesammt einen nabezu soliden Zapfen, an diesem Schnitt noch mit der regularen, wweisehichtgen epitbelialen Auskleidung des Speichelganges in continuirlichem Zusammenhang, am nächsten Schnitt schon ganz von ihr getrennt. Dieser compacte Zellhaufen liegt au isolirt inmitten der dicht infiltrirten Umgebung. Zu gleicher Zeit, d. h. am selben Sohnitt und noch mehr in den nächstfolgenden, ändert sich auch sofort die solide Beschaffenheit dieses Zellapfens. Der Grund hiefür legt in dem Verhalten einzelner Zellen. Das Proloplasma derselben, bisher mit Bämatoxylin-Eosin roth gefäbt und stark granulirt, ändert seine Körnelung, nimmt eine ganz loicht angedeutete lichtblaue Fäbung an, verschwimmt und quillt auf. Der Kern, an manchen dieser Zellen noch dentlich kennbar, rund oder oval, dunkelschwarzblau gefärbt, tingirt sich an anderen obenfalls viel schwächer, wird undentlich und versebwindet ganz. Es entgteben also inmitten des Zellzapfens Aveolen, mit Schleim erfullt, von Zellen worgent, 3-5 auf einem Quersehnit (Taf. II, Fig. 3c), ein- oder zweimal auch confluirend und dann wieder ein quergetroffenes Lumen vortäuschend.

In dieser Weise, im bunten Wechsel dieser verschiedenen Zelldegenerationstadien ziebt sich der Zellzapfen noch durch weitere 5-6 Schnitte, immer inmitten der dichten kleinzelligen Infiltration. Von dem ibm zum Ausgrangspunkt dienenden Speichelgang bleibt er dabei vollständig getrennt.

Im 7.-9. Schnitt nimmt er dann an Umfang beträchlich ab und versehwindet im 10. oder 11, gänzlich, was also das Enden desselben in Form einer halbirugligen Kuppe bedeutet. Die Infiltration um ihn geht continuirlich in die um den normalen Speichelgang über und verhält sich wie diese. Der Speichelgang selbst zieht nohmlich ganz für sich, vollständig normal, mit regulärer zweischichtiger epithalialer Auskleidung, inmitten der begleitenden Infiltration seiner Wege. Letztere wird übrigens schwächer und werschwindet nach weiteren 10-12 Schnitten vollständig aus der Umgebung des wieder normalen Speichelganges.

Andere Speichelgange bieten dieselben Veränderungen in analoger Weise über 5-10-20 Schnitte sich orstreckend. Infiltrate und Epithelveränderungen verbalten sich ganz gleich wie im beschriebenen Theil, nur sind die Veränderungen nicht überall so scharf ausgeprägt.

Bei der Beschreibung und noch mebr bei anmittelbarer 
Besichtigung dieser Veränderungen fällt die grosse Aehnlichkeit, um nichtzusagen Identitätderselben mitjenen Vacuolenbildungen auf, welche wir an den soliden Zellzapfen des das byaline Bindegewebe durchwuehernden Tuwors I beobachteten und welche, wie erwähnt, in gleicher. Weise auch im Tumor II sich finden. (W ir führten auf sie ja einen Theil der drüsenähnlichen Bildungen in diesen Tumoren, sowie einen Theil der eigenthümlichen schleimerfüllten, charakteristischen Hohlräume zurück.) Die Aehnlichkeit ist unverkennbar.

Ich glaube nun nicht fehlzugehen, wenn ich die soeben beschriebenen epithelialen Veränderungen, beobachtet an Speichelgängen inmitten ganz normalen Parenchyms und begleitet von frischer Infiltration, als ganz junge Stadien der eylindromatösen Neubildung betrachte; als ganz jung, weil man noch ihren Ausgangspunkt vom Normalen sieht und sie ja mitten im Normalen liegen; als Theile der Neubildung, weil eben zwischen ibnen einerseits und ausgedehnten, dem Tumor angehörigen Gebilden andererseits absolut kein Untersehied constatirbar ist.

Demgemäss halte ich den Beweis für die rein epitheliale Herkunft der zelligen Elemente auch dieses Tumors II für sicher erbracht, indem ich deren Entstehungsort in die epitheliale Auskleidung der Ausführungs- und Speichelgänge der Glandula submaxillaris verlege. Auch hier rechtfertigt das schrankenlose Wachsthum des Tumors in die Umgebung mit Zerstörung derselben und die epitheliale Genese desselben in histologischer Beziehung die Bezeichnung "Carcinoma", dazu auf Grund des morphologischen Verhaltens weitaus der meisten Antheile dieses Tumors mit dem Attribut "cylindromatosum".

Hervorzuheben ist noch, dass auch in diesem Falle mitten im compacten Tumor eine Anzahl Nervenfasern angetroffen wurde, welche verschiedene Compressionserscheinungen darboten, und auf welche also auch hier die Schmerzen in der Nachbarschaft zu beziehen șind.

Im Folgenden fasse ich in Kürze die Ergebnisse meiner Untersuchung zusammen:

I. Die Tumoren der Submaxillarisgegend gehören nicht zu den alltäglichen. Unter ihnen nehmen an Zahl nächst den Mischgeschwülsten die Cylindrome den ersten Platz 
ein. Ich konnte deren 8-9 ausfindig machen und füge hier zwei eigene Beobachtungen hinzu.

II. Der klinische Charakter dieser Tunoren ist ein wechselnder. Allen gemeinsam, ohne Auswhme, ist das langsame Wachsthum, dessen Beginn vonden Patienten oft in die Kindheit verlegt wird und sich meist über viele Jahre hinaus erstreckt. Bezüglich des Grades ihrer Bösartigkeit aber differiren die beobachteten Fälle unter einander. Santesson's und Franke's Tumoren wurden durch die Exstirpation radical geheilt. Nasse's Fall reoidivirte nach der 1, unvollstïndig answ geführten Operation; nach endgüItig ausgeführter Exstirpation blieb der betrefiende Pat. recidivfrei. Ewald's and Barth's Fälle recidivirten nach der 1. Operation, Ewetzky's Fall I recidivirte $2 \mathrm{mal}$. Ewetzky's Fall II und Klebs' Fall (welche eventuell identisch sind) recidivirten $2 \mathrm{mal}$ und führten durch langdauernde Kachexie den Tod herbei. Dasselbe gilt für den Fall Tommasi's, in welchem bei der Autopsie obendrein noch Metastasen in den Lymphdrüsen und in der Leber zu constatiren waren.

Es ergiebt sich also: bei ungefähr gleich bleibendem histologischen Charakter eine grosse Differenz im klinischen Verhalten, so dass in einem Extrem die Tumoren relativ gutartig, im anderen sehr bösartig sein können. Wenn man nun auch in ungeren Fällen wegen der Kürze der nach der Operation verllossenen Zeit kein endgültiges Urtheil über den klinischen Charakter der beiden Tumoren fällen darf, so orgiebt sich doch in beiden eine aufallende Incongruenz zwischen anatomischem und klinischem Verhalten. Da sio langsam gewachsen sind und lange Zeit nahezu stationär blieben, da die von ihnen verursachten Beschwerden sich auf rein locale Verdränguagserscheinungen, und die allerdings heftigen Schmerzen in der Umgebung sich auf mechanische Nervencompression zurückführen lassen, da ferner die benachbarten lymphdrüsen immer frei blieben und das Allgemeinbefinden der Patienten immer ein sehr gutes war, so kann manklinischjedenfalls von einer exquisiten Malignität nicht sprechen, wenn man auch diese Tumoren nicht als unbedingt gutartig hinstellen kann; denu die seit der Operation verflossene Zeit ist zu minimal, um nicht etwaiges Recidiviren ausschliessen zu könnea. 
Dagegen ergiebt die histologische Untersuchung, ausser den Verdrängungs- und Compressionserscheinungen an den Nerven, ein höchst evidentes actives Vordringen der Geschwulstmassen gegen die umgebenden Gebilde; die Submaxillardrüse geht zum grössten Theil im Tumor auf, die quergestreifte Musculatur wird von ihm substituirt. - Alles Kriterien, wie sie besser ausgebildet an den malignesten Carcinomen und Sarcomen nicht angetroffen werden können. Da nun aber bei diesen exquisit malignen Tumoren das klinische Bild mit dem histologischen Befund in ganz constanter Weise sich deckt, so legt eben schon die im Gegensatz hierzu in unseren Fällen bestehende Incongruenz dieser beiden Factoren für diese 2 Tùmoren eine Sonderstellung von vornherein nahe.

III. In morphologischer Beziehung bieten die Cylindrome der Submaxillargegend nichts von den für solche Tumoren andererKörperregionen charakteristischen Befunden Abweichendes. Auch unsere. Fälle reiben sich ihnen in dieser Beziehung.an, und zeigen sich demgemäss aufgebautaus $z$ wei sich durchflechtenden Balkensystemen, von denen das eine rein zelliger, das andere hyalin-schleimiger Natur ist. Abwechselung bringen hierzu noch gröbere und feinere fibrillärbindegewebige Septen, und als für unsere Fälle besonders charakteristisch zahlreiche, mit mucinhaltiger Flüssigkeit von verschiedenem Consistenzgrad erfüllte, regellos zerstreute Hohlräume.

IV. Betreffs der Genese der Submaxillarcylindrome stimmen bis jetzt die Autoren so ziemlich überein. Sie alle sind sich über die Bedeutung der zelligen Bestandtheile als der in histogenetischer Beziehung weitaus prävalirenden Componente klar und führen dieselben auf die Saftkanälchenzellen oder direct auf Lymphendothelien zurück; sie bezeichnen ihre Tumoren demgemäss als Sarcome und Endotheliome mit eigenthümlicher hyaliner Degeneration. Billroth giebt dabei ausdrücklich an, Uebergänge von der Drüse zum Tumor gesucht, aber nicht gefunden zu haben, und nur Nasse spricht sich nicht unbedingt gegen die Möglichkeit epithelialer Genese aus.

Dagegen glaube ich für die vorliegenden beiden Fälle von Submaxillarcylindromen, und zwar für Fall I mit grösster 
Wahrscheinlichkeit, für Fall II mit Sicherheit dargethan zu haben, dass der Ausgangspunkt der zelligen Wucherung in epitholialen Gebilden zu suchen sei; für Fall $I$ in den Drüsenepithelien der Acini der Submaxillar-Speicheldrüse, für Fall II in den Epithelien der grösseren Ausführungs- und kleineren Speichelgänge derselben Drüse.

Dieser Befund ist gegenüber der bisher bei derartigen Tumoren erhobenen ein never und berechtigt, im Gegensatz za den bisher beschriebenen cylindromatosen Sareomen oder Endo theliomen hier von cylindromatösen Carcinomen odez carcinomatösen Cylindromen der Submaxillardrüse zu sprechen.

7. In Bezug auf die Genese der übrigen Bestandtheile, des Hyalins der Submaxillarcylindrome insbesondere, äussern sich die Autoren iu nicht zu divergenter Weise. Sie führen dessen Entstehung auf das fibrilläre Bindegewebe, auf degenerirende Gefässe und auf Umwandelung zelliger Theile zurück. Auch unsere beiden Tumoren zeigen diesen Befunden analoge Verhältniss. Die fibrillären Septenstammenvom Bindegewebe. Gleichen A usgangspunkt haben diesocharakteristischen hyalinschleimigen Balken. Dureh vollständige schleimige Verflüsigung solcher Balken entsteht ein Theil der beschriebenen schleimerfullten Hohlräume, ist also in letzter Linie mittelbarer Abkömmling fibrillären Bindegewebes. Endich sahen wir noch einen Theil jener schleimerfülten Hohlrärme durch schleimige Umwandelung und Aufquellung einzelner Zellen entstehen, was für dieselben eine epitheliale Genese ergiebt.

\section{Erklärung der Abbildungen. \\ Tafel II.}

Fig. 1. (Zeiss Oc. 3 Obj. C.) Uebersichtbild aus dem Tumor I. a gröberes Bindegewebsseptum, theils fibrillăr, theils hyalin degenexirt (bei a'). b hyalin-schleimiges Balkenterk, zum Theil (bei $b^{\prime}$ ) in directem Zusammenhang mit hyalinen Partien des Septums a. c epitheläbnliche (Carcinom-) Zellen. ả kleinere und grössere Hoblräume mit theils klumpig $\left(d^{\prime}\right)$, theils fădig $\left(d^{\prime \prime}\right)$ geronnenem Scbleim erfüllt.

Fig. 2. (Zeiss Obj. O. Oc.3.) Grösstentheils solide Zellzapfen aus den peripherischen Theilen des Tumors I. a inmitten der Zellzanien ge- 
legene, mit Schleim erfüllte Hohlräume, in welchen noch stellenweise (bei a') Reste aufgequollener Zellen mebr oder weniger deutlich sichtbar sind. b kleiner drüsenähnlicher Zellzapfen.

Fig. 3. (Zeiss Obj. E Oc. 3.) Ein grösserer Ausführungsgang mit infiltrirter Umgebung aus dem mit dem Turoor II exstirpirten Submaxillardrüsenrest. a reguläres Epithel des Drüsenausfübrungsganges. b atypischer Epithelzellenzapfen, in continuirlichem Zusammenhang mit normalem Epithel. c kleinste schleimerfüllte Hohlräume $z$ wischen den Zellen.

\title{
VII.
}

\section{Ueber den Mechanismus des Harnblasen- verschlusses und der Harnentleerung.}

\author{
Von Dr. Eugen Rehfisch in Berlin.
}

(Mit 3 Textabbildungen.)

Der einfache, uncomplicirte Bau der Harnblase, ihre noch einfachere Function, die fast jedem Laien verständlich scheint, sollte vermuthen lassen, dass auch die Physiologie dieses Organes sich in leichter, zum mindesten nicht besonders schwieriger Weise würde deuten lassen. Allein gerade die alten und immer wieder von Neuem auftretenden Controverse über den Mechanismus der Harnentleerung geben den deutlichsten Beweis, dass gerade über dieses Capitel unter den verschiedenen Forschern keine einheitliche Anschauung herrscht. $\mathrm{Ja}_{\mathrm{a}}$ sogar über die wichtigste Prämisse jeglicher physiologischen Forschung, über die Anatomie, finden wir unter den bedeutendsten Autoren, wie bei Kohlrausch, Henle, Barkow and Hyrtl die verschiedenste Auffassung. Immer wieder sehen wir die Frage auftauchen, $o b$ der Sphincter vesicae zur Blase selbst gehört, oder ob der Blasenverschluss von anderen Organen, speciell von der Prostata, gebildet wird. Die Situation wird aber noch dadurch besonders schwierig, dass die Ergebnisse anatomischer und physiologischer Forschung sich nicht immer mit den Beobachtungen an Lebenden, sei es in normaler oder pathologischer Hinsicht, in Einklang 